\title{
HERBERT BALDUS: VIDA E OBRA INTRODUÇÃO AO INDIGENISMO DE UM AMERICANISTA TEUTO-BRASILEIRO*
}

\author{
Orlando Sampaio-Silva**
}

\begin{abstract}
SAMPAIO-SILVA, O. Herbert Baldus: vida e obra - Introdução ao indigenismo de um americanista teuto-brasileiro. Rev. do Museu de Arqueologia e Etnologia. S. Paulo, 2:91-114, 1992.
\end{abstract}

RESUMO: Herbert Baldus foi um antropólogo teuto-brasileiro que exerceu importante papel na constituição da pesquisa e dos conhecimentos antropológicos no Brasil. Seu trabalho científico se desenvolveu intimamente ligado ao curso de sua própria vida, que transcorreu, em sua maior parte, neste pais, dedicada ao ensino, à pesquisa, à divulgação cientifica e à tentativa de instituir uma política indigenista comprometida com a preservação das etnias indigenas. A contribuição de seu pensamento teórico, tendo iniciado com explanações sobre as culturas materiais e não materiais, passou por abordagens funcionalistas e estruturalistas, lançando as bases dos estudos das sociedades indígenas em situação de contato e de mudança cultural.

\footnotetext{
UNITERMOS: Vida - Obra - Indigenismo - Preservacionismo - Situação de contato - Mudança cultural.
}

A pesquisa científica e a produçāo de obras antropológicas, tendo por objeto de estudo as sociedades indigenas existentes no território brasileiro, estão inseparavelmente ligadas aos trabalhos desenvolvidos por pensadores e cientistas alemāes. $O$ exemplo da acuidade cientifica na observação e na interpretação dessas sociedades propiciado por Karl von Martius, viria a reproduzir-se, em contextos sociais e históricos posteriores, nas atividades cientificas de Karl von den Steinen, Kurt Nimuendajú e de Herbert Baldus, além de outros. Estes dois últimos pesquisa-

(*) Trabalho originalmente apresentado no Simpósio "Pesquisa antropológica de urgência e direitos dos povos indigenas face aos Estados", $47^{\circ}$ Congresso Internacional de Americanistas, 7-11/7/1991, New Orleans, USA.

(**) Universidade Federal do Pará. dores vieram a ocupar posiçōes fundamentais, exercendo decisiva influência, através de suas pesquisas e de suas obras, na orientação que viriam a tomar, no Brasil, as investigações no campo da Antropologia indígena, e, de alguma forma, na formação dos primeiros antropólogos brasileiros que se dedicaram àqueles estudos, bem como no delineamento dos aspectos positivos (entre tantos negativos contra os quais se insurgiram) do indigenismo oficial.

Herbert Baldus nasceu a 14 de março de 1899, em Wiesbaden, Alemanha. Era filho de Martin (matemático) e Carolina (de uma familia de armadores) Baldus. A obra de Baldus está intimamente ligada a sua vida. Quando a Primeira Grande Guerra Mundial (1914-1918) se aproximava de seu término, Baldus, aos 18 anos de idade, veio a integrar o Corpo Real de Cadetes de seu pais, em Potsdam, como 
SAMPAIO-SILVA, O. Herbert Baldus: vida e obra - Introduçào ao indigenismo de um americanista teuto-brasileiro. Rev. do Museu de Arqueologia e Etnologia. S. Paulo, 2:91-114, 1992.

aviador, tendo, como tal, participado daquela hecatombe. Este episódio, em sua vida de jovem, propiciou-lhe a produção de poemas centrados na temática da guerra.

Em 1921, viajou para a Argentina, vindo, assim, aventurar-se, sem objetivos específicos claramente definidos, na América do Sul. Mudou-se, em 1923, para São Paulo, no Brasil, e, neste mesmo ano, visitou os indios Xamakoko, Kaskihá e Sanapaná, do Chaco, Paraguai, como participante, então, de uma expedição cinematográfica. Esta viagem despertou, definitivamente, em Baldus, o interesse pelas regiōes distantes da civilização e pelos estudos antropológicos tendo por objeto os povos indigenas, dando, assim, os primeiros passos em sua carreira profissional como etnólogo. A esta profissão ele se dedicou, com ânimo incomum, até sua morte ocorrida em São Paulo, a 24 de outubro de 1970.

O contato com aqueles primeiros povos indigenas que observava propiciou-lhe material etnográfico para a publicação de seu primeiro artigo sobre a temática indigena, intitulado "Os indios Chamacoco" (1927). Só no ano de 1927, Baldus voltaria a estar com indios, ao visitar os Guarani, no litoral paulista, para, logo no ano seguinte, retornar ao Chaco, onde realizou nova abordagem junto aos Xamakoko, os Kaskihá e os Sanapaná.

Estas últimas visitas de observação permitiram a Baldus publicar seu primeiro artigo sobre indios Guarani ("Ligeiras notas sobre os indios Guaranys do litoral paulista", 1929), e, diversos trabalhos sobre aqueles grupos indigenas do Chaco.

Incentivado pelo êxito de suas primeiras expediçōes ao campo, Baldus, ainda em 1928, retornou à Alemanha, para formalizar seus estudos de Etnologia, na Friedrich-WilhelmUniversität, de Berlim. Neste centro de estudos superiores, seu mestre de Etnologia foi Richard Thurnwald, tendo ai também realizado estudos americanistas com Konrad Theodor Preuss e Walter Lehmann, e estudado Filosofia com Heinrich Meier, Desoir, Lieber e Spranger, vindo a conquistar o título de Doutor em Filosofia.

Quando estudante, em 1931, publicou, em Leipzig, seu primeiro livro etnográfico, intitulado Indianerstudien im nordöstlichen Chaco, tendo por objeto aqueles três grupos tribais do Paraguai (Xamakoko, Kaskihả e Sanapaná) com os quais já havia estado duas vezes, anos antes.

Dando asas ao seu espírito literário, Baldus, estudante em Berlim, produziu alguns textos, entre os quais se destacou uma novela biográfica baseada na vida da mulher do caudilho paraguaio Solano Lopes - "Madame Lynch" —, publicada em 1931.

Inconformado e se sentindo ideologicamente incompatibilizado com a ascensão do Nacional Socialismo (Partido Nazista) ao poder, na Alemanha, Baldus, um autêntico democrata-liberal-progressista - como demonstraria ao longo de toda sua existência -, deixou seu pais, em 1933, transferindo-se definitivamente para o Brasil, onde morou pelo resto de sua vida. Hans Becher (1972: 1308), a propósito deste fato, informa que "The Nazis burnt his books and deprived hin of his German citizenship". Os nazistas não perdoariam, assim, esse humanista amante da liberdade.

No mesmo ano em que retornou ao Brasil, Baldus, subvencionado pela Notgemeinschaft der Deutschen Wissenschaft (Sociedade Assistencial de Ciência Alemā), de Berlim, empreendeu uma expedição ao sul do país, visitando os Kaingang, de Palmas, no Paraná, no leste do Paraguai. Com estes indios, esteve, nesta oportunidade, à procura de um grupo local Guayaki, entāo, ainda isolado. Nesta mesma expedição, esteve, por curto espaço de tempo, com os indios Xiripá. Com bases nas observaçōes realizadas ao longo dessa expedição científica, Baldus veio publicar diversos artigos sobre os grupos visitados no Brasil e principalmente no Paraguai. Destacam-se entre esses artigos o "Sprachproben des Kaingang von Palmas" (1933), o "Sinopse de cultura guayaki" e o "The Guayaki", sendo este último em colaboração com Alfred Métraux, trabalhos que exibiram um pesquisador sobretudo arguto na observaçāo de campo e nos registros dos padrões sociais e culturais dos povos indigenas visitados, aspectos estes que viriam a caracterizar toda sua obra antropológica.

Os interesses cientificos de Baldus eram amplos, o que o levou a imiscuir-se nos estudos de diferentes campos da Antropologia. Este traço destacado de sua obra já ficou bem claro, quando, em 1934, dirigiu-se ao 
SAMPAIO-SILVA, O. Herbert Baldus: vida e obra - Introdução ao indigenismo de um americanista teuto-brasileiro. Rev. do Museu de Arqueologia e Etnologia. S. Paulo, 2:91-114, 1992.

Estado de Mato Grosso, tendo, nesta expedição, estado, pela primeira vez, em contato com os Indios Terena e com os Bororo, de Meruri e do Sangradouro; nesta oportunidade, também esteve observando as pinturas rupestres existentes em Sant'Ana da Chapada, demonstrando, então, interesse na área da Arqueologia. E, como aconteceu, em geral, na vida do pesquisador, suas observaçōes de campo foram logo aproveitadas para a elaboração de artigos, que foram levados a lume, como é o caso, por exemplo, do artigo que foi publicado no Ethnologischer Anzeiger, IV, Stuttgart, sob o titulo "Die Erbfolge der Häuptlinge bei den Tereno", “As pinturas rupestres de Sant Ana da Chapada (Mato Grosso)" (1937).

Baldus voltou, em 1935, a Mato Grosso, subvencionado pelo dr. Samuel Ribeiro, por intermédio do Instituto Histórico e Geográfico de São Paulo, para prosseguir os estudos sobre os Bororo, desta vez, os Tóri-páru, vindo, então, também, a iniciar suas observaçōes etnológicas entre os indios Karajá, da Ilha do Bananal, no rio Araguaia, e entre os Tapirapé. Para atingir este grupo, Baldus partiu da Ilha de Bananal e seguiu de canoa pelo rio Tapirapé até a aldeia Tampiitaua, daqueles indios. Wagley (1980) informa que "Sua (de Baldus) experiência real de campo entre os Tapirapé estava limitada a cerca de seis semanas em 1935 e ainda mais um curto periodo em 1947".1

Estava definitivamente estabelecida uma das principais caracteristicas do trabalho científico de Baldus, ou seja, seu interesse pelos estudos de um grande numero de grupos indígenas, ao invés de tornar-se um especialista, exclusivista, em um único grupo, orientação dominante essa que lhe valeu tornar-se um dos mais expressivos conhecedores dos grupos indigenas do Brasil, com base na sua própria experiência de pesquisa de campo. Assim, ampliando a divulgação de seus estudos sobre a pluralidade de sociedades indigenas, publicou, em 1937, um interessantíssimo ensaio sobre "A posição social da mulher entre os Borôros Orientais" (Baldus, 1937).

Baldus voltou aos Tapirapé em 1947 -

(1) Texto prơduzido para a comemoração do décimo aniversário do falecimento de Baldus. cf. foi referido anteriormente em citação de Wagley. As permanências com estes indios propiciaram ao pesquisador o registro de um volume tāo abundante de informaçōes, que pôde produzir sua obra mais alentada em Etnologia e da maior importância em sua bibliografia, tal seja o Tapirapé - Tribo tupi no Brasil Central (1970), ou, cf. Hans Becher (1972), "His later monogaph on the Tapirapé became his most significant book".

Suas visitas aos Karajá levaram-no a interessar-se por um dos aspectos mais simbólicos e esteticamente insólitos da cultura material desse povo, as bonecas calipigias de cerâmica, tendo publicado, logo em 1936, o artigo "Licocós, as bonecas dos Carajás".

Em 1937, reunindo em um volume diversos trabalhos, Baldus publicou uma de suas obras mais importantes, os Ensaios de Etnologia Brasileira, contendo oito ensaios, com os seguintes títulos: "Etnologia Brasileira" (pp. 17-28). "O culto aos mortos entre os Kaingang de Palmas" (pp. 29-69), "A sucessão hereditária do chefe entre os Tereno" (pp. 70-85), "Os grupos de comer e os grupos de trabalho dos Tapirape" (pp. 86-111), "A posição social da mulher entre os Bororo Orientais" (pp. 112-162), "O professor Tiago Marques e o caçador Aipoburéu" (pp. 163186), "Mitologia Karajá e Tereno" (pp. 187275) e "A mudança de cultura entre indios no Brasil" (pp. 276-321). Este livro extremamente rico, tanto do aspecto teórico, quanto da apresentação e descrição de dados empíricos, Baldus dedicou "Ao grande conhecedor dos indios no Brasil Curt Nimuendajü".

Já com uma significativa experiência acumulada de pesquisas etnológicas, Baldus, em 1939, assumiu a cadeira de Etnologia Brasileira, na Escola de Sociologia e Politica de São Paulo, a convite de Antônio Rubbo Müller (cf. este professor), tendo lecionado no periodo mais brilhante da vida deste estabelecimento pioneiro no ensino e na pesquisa em Ciências Sociais, no Brasil. Através do periódico Sociologia, da Fundação Escola de Sociologia e Politica de São Paulo FESPSP - (no qual era o diretor da "secção etnológica"), Baldus divulgou muitos de seus estudos, dentre os quais queremos registrar os diversos artigos com "sugestōes para pesquisas etnográficas". Na FESPSP, Baldus dirigiu o Seminário sobre os Indios no Brasil, 
SAMPAIO-SILVA, O. Herbert Baldus: vida e obra - Introdução ao indigenismo de um americanista teuto-brasileiro. Rev. do Museu de Arqueologia e Etnologia. S. Paulo, 2:91-114, 1992.

e esteve vinculado a esta instituiçāo - embora não lecionando ai de forma continua até sua morte (cf. A. Rubbo Müller, em depoimento pessoal). Nos cursos e seminários que dirigiu na Sociologia e Política, foram, de uma forma ou de outra, seus discipulos algumas pessoas que vieram a ocupar lugares da maior importância nas ciências sociais, no Brasil (alguns com renome internacional), entre estes: Oracy Nogueira (mestre em 1945), Gioconda Mussolini (idem), Virginia Leone Bicudo (idem), Lucila Hermann (mestre em 1946), Florestan Fernandes (mestre em 1947), Fernando Altenfelder Silva (mestre em 1949), Levy Cruz (mestre em 1951), Sérgio Buarque de Holanda (mestre em 1958), Darcy Ribeiro, Juarez Barandão Lopes, Cândido Procópio Ferreira de Camargo, Alfonso Trujillo Ferrari, Egon Schaden, João Baptista Borges Pereira, David Maybury-Lewis, Roberto Cardoso de Oliveira. ${ }^{2}$

Ampliando seu campo de interesses nos estudos sócio-antropológicos, Baldus, em companhia de Emilia Willems e de alunos da Escola de Sociologia e Politica, dirigiu-se ao vale do Ribeira de Iguape, no Estado de São Paulo, para estudar as manifestações sócioculturais, em especial a mudança cultural, no grupo de imigrantes japoneses estabelecido nesta área. Como consequência dessa expedição, Baldus veio a publicar, em colaboração com Willems, o artigo "Casas e túmulos de japoneses no vale da Ribeira de Iguape" (1941). No mesmo ano da publicação desse trabalho, Baldus naturalizou-se brasileiro, adotando, dessa forma, definitivamente, o Brasil como sua segunda pátria.

Empolgado com a questão da pré-história americana, Baldus, em 1944, retorna à pesqui-

(2) Charles Wagley (1980) revela que "Herbert Baldus foi de inicio meu professor (apesar de nunca ter estado formalmente com ele)...". Por sua vez, o autor do presente ensaio, quando fez seus estudos de pós-graduação em antropologia, na Escola Pós-Graduada de Ciências Sociais, da Fundaçāo Escola de Sociologia e Política de São Paulo, nāo teve o privilégio de contar com Baldus entre seus professores, porque ele se encontrava inativo naquela Escola à época (1964-65); porém, teve a satisfação de conhecê-lo pessoalmente, de privar de sua palestra inteligente, em visita ao seu gabinete de trabalho, no alto do Museu Paulista (USP), e de participar com o mesmo de eventos cientificos. sa arqueológica, ao proceder escavaçōes em sítios no Estado do Paraná. Fez explanaçōes descritivas e análises interpretativas da parte gráfica e decorativa em cacos de cerâmica, então, encontrados, na bacia do rio Paranapanema, estudo que apresentou em "Tonscherbenfunde in Nordparaná" (1951/52).

Dois anos depois, dando prosseguimento a suas pesquisas etnológicas de campo, visitou os indios Kaingang do Ivaí, no Paraná, quando fez registros sobre a mitologia desse povo vindo a publicar logo a seguir o artigo "Os Kaingang do Ivai" (1947) - e procedeu a discutiveis aplicaçōes de testes psicológicos projetivos entre aqueles indios. Este trabalho foi procedido com o apoio e a orientação da psicóloga Aniela Ginsberg, que realizou a interpretação psicológica dos testes aplicados por Baldus em um grupo sexualmente misto de 32 Kaingang. A parte de campo foi realizada exclusivamente por Baldus. $O$ resultado destes estudos foi divulgado através do artigo: "Aplicaçāo do psicodiagnóstico de Rorschach a indios Kaingang" (1947). Cícero Christiano de Souza (1953) narra, em cores vivas, a história desses testes: "O material cuja análise vai ser apresentada neste trabalho tem uma história complicada. Foi colhido pelo Prof. Herbert Baldus, em maio-junho de 1946, durante uma viagem ao Ivai, subvencionada pela Escola de Sociologia e Política de São Paulo. Foram os protocolos entregues à Dra. Aniela Ginsberg, que fez sua análise. A Revista do Museu Paulista publicou, em 1947, um artigo de autoria, parte de Baldus e parte de Ginsberg, no qual são relatadas pelo primeiro as peripécias da obtenção do material, e pela última, a análise do mesmo.

"O Prof. Baldus, todavia, não ficou inteiramente satisfeito com a interpretação de Ginsberg, parecendo-lhe que os resultados por ela apresentados não correspondiam à realidade psicológica que ele, antropólogo, tinha podido observar direta e concretamente. Pediume, então, que re-analisasse os protocolos, que me foram entregues no começo de 1948. Como nessa ocasião, devia eu ir para os Estados Unidos trabalhar num hospital de que Douglas Kelly era diretor, resolvi levá-los comigo para que esse mestre do Rorschach tomasse parte em sua análise. ... Sendo eles escritos em português, servia eu de intérprete obrigatório. Kelly convidou também Joseph 
SAMPAIO-SILVA, O. Herbert Baldus: vida e obra - Introdução ao indigenismo de um americanista teuto-brasileiro. Rev. do Museu de Arqueologia e Etnologia. S. Paulo, 2:91-114, 1992.

Grassi, professor de Psicologia Clínica, para colaborar conosco. ... A apuração ia ainda a meio caminho quando Kelley mudou-se de Winston-Salem, onde estávamos, para Berkeley, onde foi ser diretor da Escola de Criminologia da Universidade da Califórnia. Grassi, que nunca estivera muito interessado no trabalho, também o abandonou nessa ocasião. Tínhamos, então, apurado exatamente a metade dos protocolos, ou seja, 16 dentre os 32 ...

"Continuei sozinho a fazer a análise e, algum tempo depois de voltar ao Brasil, discuti com o Prof. Baldus os resultados a que chegara (com ou sem a colaboração de Kelley e de Grassi). Pareceu-lhe que esses resultados estavam mais de acordo com suas próprias observaçōes, pensando ele que deveriam ser publicados. "Eu próprio não tinha o mesmo entusiasmo de Baldus, por várias razōes. A mais importante é que, devido às enormes dificuldades da administração, foi esta muito defeituosa. Torna-se, por isso, extremamente difícil analisar de maneira bem precisa um grande número de respostas, o que dá à interpretação final uma margem de erro bastante apreciável. Fiquei, pois, em dúvida quanto à vantagem de publicar um material dessa natureza, sobretudo depois de já ter sido uma vez analisado. Baldus, contudo, insistiu sempre em sua publicação, convencendo-me, enfim, a fazê-la" (Souza, 1953). Ao procedermos essa longa citação, o fazemos por sua propriedade como testemunho histórico de um episódio incomum na vida de Baldus, mas, também, como um exemplo dos caminhos incertos pelos quais um trabalho científico não deve trilhar. $\mathrm{O}$ próprio Baldus, como era de se esperar, viria, mais tarde, a penitenciar-se, quando, em seu conspícuo estudo sobre o xamanismo (1965/66), assim se pronunciou: "Mesmo as técnicas projetivas como os psicodiagnósticos de Rorschach e Mira Y Lopez, aplicados por mim, em 1946, a indios Kaingang, impōem, usadas fora da nossa cultura, tantas restriçōes que não me parecem recomendáveis" (Baldus, 1965/66).

Baldus foi convidado, pelo Governo de São Paulo, para organizar as coleçōes do Museu Paulista, em 1946, e alguns meses depois desse convite, aquele mesmo governo confioulhe a direção da Seção de Antropologia do mesmo Museu. A partir de então, Baldus editou a Revista do Museu Paulista, tendo sido publicado, em 1947, o volume I da Nova Série deste que é um dos mais importantes periódicos no campo da Antropologia editados no Brasil. Através dessa Revista, alguns dos mais importantes trabalhos cientificos de Baldus vieram a lume, conforme pode ser constatado na bibliografia desse autor que compōe este artigo. Baldus permaneceu naquela função pelo resto de sua vida.

Em 1947, Baldus desenvolveu intensas atividades de pesquisa. Na primeira metade do ano, esteve com outro grupo Kaingang, o de Icatu, em Sāo Paulo, e com outro grupo Terena, o de Araribá, também neste Estado; nos meses de junho, julho e agosto, convidado pelo Serviço de Proteção aos Indios, visitou aldeias dos indios Karajá, da ilha do Bananal - Goiás - e de Mato Grosso, bem como esteve, em curta estada (cf. foi referido anteriormente), novamente com os Tapirapé, do rio Tapirapé, Mato Grosso. Nessas visitas, Baldus representava o Museu Paulista e a Escola de Sociologia e Política, e estava acompanhado do médico Haroldo Cândido de Oliveira. $\mathrm{O}$ relatório que Baldus produziu para 0 S.P.I., em decorrência desta última viagem, apareceu publicado na Revista do Museu Paulista, N.S., Vol. II, 1948. Contém criticas severas ao Serviço de Proteção aos Indios, oferece sugestões extremamente sérias ao indigenismo brasileiro, e contém preciosas informações etnológicas sobre os vários grupos locais Karajá e Tapirapé que visitou. Refere-se à "natureza morta" da aculturação, quando fala do uso pelos Karajá de panela de ferro - que substitui à de barro - e, sapato de couro, objetos originários da influência dos brancos. Faz críticas à implantação da escola de nossa sociedade nas sociedades indigenas e lembra o caso do índio Bororo professor Tiago Aipoburéu em processo de alienante decadência; ${ }^{3}$ critica também a ação dos catequistas religiosos, por sua influência negativa nas sociedades visitadas. Fala da inconveniência do uso pelos indios de vestuário levado pelos bran-

(3) O caso desse indio Borôro foi exposto por Baldus no ensaio "O professor Tiago Marques e o caçador Aipoburéu" (in Ensaios de Etnologia Brasileira, 1937). O mesmo tema foi retomado por Florestan Fernandes, quando, em 1945, escreveu o trabalho "Tiago Marques Aipoburéu: Um Boròro marginal”, para o Seminário sobre os indios no Brasil, dirigido por $\mathrm{H}$. Baldus. 
SAMPAIO-SILVA, O. Herbert Baldus: vida e obra - Introduçāo ao indigenismo de um americanista teuto-brasileiro. Rev. do Museu de Arqueologia e Etnologia. S. Paulo, 2:91-114, 1992.

$\cos$, por sua inadequaçāo aos trópicos. Analisa a política de "administração direta" aplicada pelo S.P.I. ("pacificando as hostis e acaboclando as outras") e pela tradição portuguesa e francesa, inclusive na África ("procurar substituir a cultura indigena pelas nossas instituiçōes, conceitos e língua"), enquanto a "administraçāo indireta" empregada nas colônias inglesas "conserva a cultura indígena o mais possivel...". Encontra os fundamentos doutrinários da "administração direta" no positivismo comteano, do qual Rondon era seguidor, sendo essa orientação teórica herdeira do pensamento evolucionista (pp. 162/3). Entre muitas recomendaçōes e críticas, condena: a intervenção na economia tribal; construçōes de casas para indios pelo S.P.I.; a presença de ladrōes de terras, mascates, turistas, caçadores brancos e de jornalistas e cinematografistas em aldeias indigenas. Baldus recomenda a realização de cursos, que preparem os funcionários do Serviço de Proteção aos Indios para lidarem com os povos indigenas (pp. 166/7/8).

O ano de 1949 foi particularmente intenso. Convidado pelo governo norte-americano, Baldus excursionou a diversas tribos de índios dos Estados de Arizona e New México, nos Estados Unidos, onde também visitou bibliotecas e museus. Foi eleito secretário do Comitê Executivo do XXIX Congresso Internacional de Americanistas, que se realizou em New York. Em São Paulo, neste mesmo ano, recebeu duas distinçōes: Medalha Tobias de Aguiar, que the foi conferida pelo Governo do Estado, e a Medalha Goetheana, que lhe foi agraciada pela Sociedade Goetheana daquele Estado. Ainda nesse ano, Baldus prefaciou a obra de Florestan Fernandes: Organização Social dos Tupinambá, vindo aquele prefácio a ser publicado, em outros veículos de comunicação, sob o título: "Etno-Sociologia brasileira" (1949) (conforme bibliografia de $\mathrm{H}$. Baldus levantada exaustivamente neste estudo).

Nesse ensaio, Baldus faz uma sintese das contribuições de cronistas, missionários e viajantes para o conhecimento das populaçōes tribais existentes no Brasil, desde Pero Vaz de Caminha até seus (de Baldus) contemporâneos; refere-se a von Martius como o "pai da Etnologia Brasileira", por seu Beiträge zur Ethnographie und Sprachenkunde Amerikas zumal Brasiliens (1867), e, ao Pe. Colbacchini, como "o primeiro pesquisador de indios do
Brasil, que merece, até certo ponto, o nome de étno-sociólogo", por sua monografia sobre os Borôro Orientais; sobre o autor prefaciado, Baldus diz que "foi a alma daquele Seminário (refere-se ao Seminário de Etnologia Brasileira, da Escola de Sociologia e Politica de S. Paulo), mostrando-se capaz de discutir com rara penetração qualquer assunto apresentado e revelando-se um dos mais esperançosos cientistas sociais brasileiros da nova geração". Tratando de tema semelhante, Baldus e Florestan Fernandes viriam a polemizar, mais tarde, em decorrência da publicação pelo primeiro, no Suplemento Literário no 159 , da edição de 28/09/59, de $O$ Estado de São Paulo, sob o título "A Etnologia Histórica no Brasil", de um comentário ao livro de Fernandes intitulado A Etnologia e a Sociologia no Brasil (1958). Neste artigo, Baldus parte de consideraçōes a respeito do primeiro capítulo do livro - Tendências teóricas da moderna investigação etnológica no Brasil - e provocou uma forte reação do autor, através do artigo "A 'Etnologia Histórica' no Brasil" (notar para a repetição do título), publicado no Suplemento Literário no 166, daquele mesmo diário paulista, edição de 23/01/60.

Ainda em 1949, com base nas observaçōes que realizou na área do Araguaia, em anos anteriores, Baldus publicou, em Freiburg/Suiça, o artigo "Akkulturation im Araguaya-"Gebiet", no qual aborda as questōes de aculturação dos indios Karajá e dos Tapirapé, confrontando dados registrados na excursão de 1935 e os de 1947, constatando grandes alteraçōes nas culturas daqueles povos. ${ }^{4}$

Em 1952, Baldus realizou, certamente, sua última pesquisa de campo entre grupos indígenas do Brasil, ao visitar os indios Kaingang de Nonoai e Guarita, bem como, os Mbyá-Guarani, também, de Guarita, no Estado do Rio Grande do Sul; no mesmo ano ele publicaria o "Breve noticia sobre os MbyáGuarani de Guarita". Também neste ano, Bal-

(4) Baldus, altamente interessado na temática da aculturação e mudança cultural, abordou este tema em muitos de seus trabalhos, como, v.g., em: "A mudança de cultura entre indios no Brasil" (in Ensaios de Etnologia Brasilei-

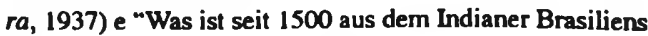
geworden?" (1962), entre outros. Neste último trabalho, estuda os comportamentos reciprocos entre indios e brancos desde 1.500, e as questōes de mudança cultural. 
SAMPAIO-SILVA, O. Herbert Baldus: vida e obra - Introdução ao indigenismo de um americanista teuto-brasileiro. Rev do Museu de Arqueologia e Etnologia. S. Paulo, 2:91-114, 1992.

dus participou da Comissão Examinadora, na defesa da tese de doutoramento de Florestan Fernandes - A função social da guerra na sociedade Tupinambá - , na II Cadeira de Sociologia, da Faculdade de Filosofia, Ciências e Letras, da Universidade de São Paulo, dissertaçāo essa que foi dedicada pelo autor a Baldus e Roger Bastide. Neste ano, particularmente movimentado, Baldus partiu para a Europa, onde visitou instituiçōes culturais e cientificas, bibliotecas, museus, em diversos países, a saber: Alemanha, Áustria, França, Dinamarca, Inglaterra, Suécia, Suiça, Espanha e Portugal. Nesta oportunidade, Baldus participou do XXX Congresso Internacional de Americanistas, em Cambridge, Inglaterra, onde representou o Governo brasileiro e foi eleito Vice-Presidente Honorário do conclave e secretário do seu Comitê Executivo. Neste evento, Baldus apresentou um trabalho sobre "Supernatural Relations with Animals among Indians of Eastern and Southern Brazil".

Em 1953, Baldus participou, em São Paulo, do II Congresso Latino-Americano de Sociologia. Neste mesmo ano, foi realizada a I Reuniāo Brasileira de Antropologia, tendo Baldus sido eleito Presidente deste conclave dos antropólogos brasileiros. Baldus participou das cinco Reuniões Brasileiras de Antropologia seguintes, realizadas, respectivamente, em Salvador (1955), Recife (1958), Curitiba (1959), Belo Horizonte (1961) e São Paulo (1963). Baldus foi eleito o Presidente da Reunião de São Paulo e, na de Belo Horizonte, já havia sido eleito Presidente da Associação Brasileira de Antropologia - ABA, para o biênio 1961-1963.

No ano do IV centenário de São Paulo 1954 -, Baldus organizou o XXXI Congresso Internacional de Americanistas, nesta cidade, pois era o Presidente da Comissão Organizadora deste congresso, que o elegeu Secretário-Geral do Comitê Executivo, conseqüentemente, membro do Conselho Permanente dos Congressos Internacionais de Americanistas, a partir de então. Ele participou, subseqüentemente, destes importantes conclaves internacionais até o XXXVII, que se realizou na Argentina, no qual, com Egon Schaden, coordenou o Simpósio sobre Aspectos Etnográficos de Culturas Indigenas do Brasil. Baldus participou e foi eleito Vice-Presidente do Comitê Executivo de diversos Congressos Inter- nacionais de Americanistas organizados sucessivamente em Copenhagen (XXXII 1956), São José da Costa Rica (XXXIII 1958), Viena (XXXIV - 1960), México (XXXV - 1962) e na Espanha (XXXVI 1964). Do XXXVII Congresso, Baldus, doente, não pôde participar, tendo sido, no entanto, eleito, na Alemanha, mais uma vez, seu VicePresidente, e o discurso que pronunciaria, então, foi lido por Schaden (em 1968).

Voltado para o intercâmbio cientifico e para a divulgação dos conhecimentos antropológicos, Baldus, com muita liderança, participou ativamente de muitos outros congressos científicos, tais como: IV Congresso Internacional de Ciências Antropológicas e Etnológicas, em Viena, no ano de 1952, no qual foi eleito membro do Conselho Permanente; Congresso de História, em São Paulo, 1954; III Congresso Mundial de Sociologia, representando a Sociedade Brasileira de Sociologia, Amsterdam, 1956; V Congresso Internacional de Ciências Antropológicas e Etnológicas, do qual foi o Vice-Presidente, Philadelphia, 1956; II Congresso Nacional de História, Lima, 1958; VI Congresso Internacional de Ciências Antropológicas, Paris, 1960, e do Simpósio "O Japonês em São Paulo e no Brasil", no qual presidiu uma das sessões, em São Paulo, 1968, conclave no qual o autor desta Introduçào foi o relator dos temas.

Editada pela Comissão do IV Centenário de São Paulo, saiu a lume o primeiro volume da importante Bibliografia Crítica da Etnologia Brasileira (1964), de autoria de Baldus, que a apresentou ao Congresso Internacional de Americanistas, então reunido em São Paulo (cf. registro anterior). Este volume veio a ser reeditado - 2a edição - , em Liechtenstein (1970). O segundo volume da Bibliografia Crítica da Etnologia Brasileira, organizado por Baldus, foi publicado em Hannover (1968). Após a morte de Baldus, foi editado por Hans Becher, em Berlim, o volume III da Bibliografia Crítica (1984), nesta oportunidade, de autoria de Thekla Hartmann, que observou a mesma orientação metodológica adotada por Baldus nos volumes anteriores. Os dois volumes editados por Baldus contêm 2.834 trabalhos, nos diversos campos da Antropologia, apresentados e comentados sinteticamente, cobrindo toda a história da Etnologia Brasileira até 1967. O volume organizado 
SAMPAIO-SILVA, O. Herbert Baldus: vida e obra - Introdução ao indigenismo de um americanista teuto-brasileiro. Rev. do Museu de Arqueologia e Etnologia. S. Paulo, 2:91-114, 1992.

pela professora Thekla Hartmann - antropóloga que sucedeu a Baldus na direção da Divisão de Etnologia, do Museu Paulista -, dando seguimento à obra paciente, minuciosa e exaustiva do mestre, contém a apresentação de 1.765 trabalhos antropológicos publicados após os que figuram no segundo volume da Bibliografia. Thekla Hartmann, na Introdução a seu Volume, diz que "O maior legado de Herbert Baldus às geraçōes mais moças de pesquisadores foi, sem dúvida, a Bibliografia Crítica da Etnologia Brasileira", e Hans Becher, no Prefácio a esse mesmo Volume, refere: "Espero que o três volumes da Bibliografia Crítica da Etnologia Brasileira sejam proveitosos para as gerações presentes e futuras de cientistas e estudantes que se dedicam à etnologia no Brasil. Devem eles recordar-se sempre do excelente compêndio que lhes foi deixado por Herbert Baldus e Thekla Hartmann, num trabalho imenso combinado com conhecimentos profundos".

Ainda em 1954, no artigo "Os Oti", Baldus aborda a questāo deste grupo indigena da região do rio Paranapanema, já, então, extinto. Apesar das diferenças sócio-culturais entre os grupos Xavantes de Mato Grosso e os Oti, Baldus refere-se a estes como os "Xavantes de São Paulo" e atribui a extinção destes indios ao confronto entre culturas, decorrente do encontro com os "brancos", o que teria provocado um "choque cultural".

A partir de 1955, Baldus foi membro correspondente da Sociedade Suiça de Americanistas. Aliás, foi reconhecido, por sua destacada contribuição ao desenvolvimento dos estudos antropológicos sulamericanos, por muitas entidades cientificas, culturais e profissionais de diversos paises, que o agraciaram com comendas ou o inscreveram nos quadros de seus filiados eméritos. Dessa maneira, Baldus era membro honorário do Real Instituto Antropológico da Grã Bretanha e Irlanda, da Sociedade Berlinense de Antropologia, Etnologia e Pré-história, da Sociedade Etnológica de Hannover e da Sociedade Antropológica de Viena. Também foi membro correspondente da Sociedade de Geografia de Lisboa. Era membro emérito do Instituto Histórico e Geográfico de São Paulo, e, foreign fellow da Associação Antropológica Americanista. Foi membro do Conselho Permanente da União Internacional das Ciências Pré-Históricas e Proto-Históricas, e, durante anos, integrou o Conselho Científico da Associação Brasileira de Antropologia. Baldus foi identicamente distinguido, quando, $\mathrm{em}$ 1958, a Prefeitura do Distrito Federal the conferiu a Medalha Silvio Romero; em 1960, a Sociedade Geográfica Brasileira lhe conferiu a Medalha Marechal Cândido Mariano da Silva Rondon, e, em 1964, foi agraciado pela Espanha com a Comenda de Isabel, a católica.

Em geral, nas oportunidades em que participou de eventos no exterior, Baldus estendeu sua viagem a outros paises, para visitar instituições cientificas. Dessa forma, em 1952, esteve em Portugal, Espanha, França, Alemanha, Suiça, Dinamarca, Suécia e Inglaterra. Quatro anos depois, voltou à Europa, para estar novamente na Alemanha, Suiça e Dinamarca, bem como, na Itália e na Holanda, estendendo sua viagem ao continente americano, onde visitou os Estados Unidos, o Equador e o Peru. Em 1958, visitou outros paises hispano-americanos, tendo estado com grupos indigenas e observado ruínas arqueológicas no Peru, Costa Rica, Honduras, Guatemala e México. Voltou ainda uma vez à Europa, em 1960 , ocasiāo em que revisitou alguns países, tais como a Áustria, a Alemanha, a Itália e a França; nesse último país, nesta oportunidade, integrou um grupo internacional de estudiosos, que visitou cavernas pré-históricas. Em 1961, retornou ao México, onde visitou sítios arqueológicos pré-colombianos. Suas viagens de estudo ao exterior levaram-no a produzir alguns trabalhos especificos, que foram publicados, tais como: "Um indigenista do Brasil no sudeste norte-americano" (1951) e "Primitivos da Argentina" (1954) (V. bibl. de Baldus, no corpo deste estudo).

Nota-se em Baldus interesse especial pelos autores de lingua alemã, particularmente os alemães que contribuiram com ensaios em língua germânica, ao conhecimento dos índios do Brasil, como se percebe claramente em seu trabalho "Beiträge in deutscher Sprache zur Indianerforschung in Brasilien (1954-1958)" (1959). Porém, seu interesse e dedicação ao estudo das obras de autores estrangeiros, bem como a sua divulgação, evidentemente, transcendia a esse grupo de escritores; em 1969, Baldus veio a publicar o ensaio "Schweizer als Indianerforscher in Brasilien”, no qual apresenta, cataloga e comenta um bom número de "americanistas" suiços. 
SAMPAIO-SILVA, O. Herbert Baldus: vida e obra - Introdução ao indigenismo de um americanista teuto-brasileiro. Rev. do Museu de Arqueologia e Etnologia. S. Paulo, 2:91-114, 1992.

De 1953 a 1960, H. Baldus foi o Diretor do Museu Paulista (também conhecido como Museu do Ipiranga), função da qual se afastou para dedicar-se exclusivamente às atividades científicas, de vez que os encargos administrativos interferiam de forma negativa em seu campo de trabalho principal. Ao contrário do que ocorreu nos demais anos, no ano de seu afastamento da direção do Museu Paulista, Baldus levou ao público um número menor de trabalhos, tendo publicado apenas dois, sendo um no Jornal do Folclore ("Curt Nimuendajú") e outro na revista Anhembi (“Antropologia Aplicada e o indigena brasileiro”). Neste último trabalho, o autor, após citar Darcy Ribeiro, em seu ensaio importante de 1957 ("Culturas e línguas indigenas do Brasil", in Educação e Ciências Sociais, II, no 6, Rio de Janeiro), no trecho em que este antropólogo faz comentários a respeito da integração dos índios Fulniô, de Pernambuco, expōe a seguinte crítica característica de seu temperamento polèmico: "Deixando de lado a discussão sobre possibilidades de reconstruçāo da "antiga cultura" em aprêço e sobre a propriedade do têrmo "obsolescências" para designar as línguas e as culturas dos povos da América do Norte, da Europa e do Brasil acima mencionados, acho que a generalização de estarem as culturas $e$ as línguas indigenas brasileiras "destinadas a se descaracterizarem na medida em que a sociedade nacional cresça" revela encarar o autor êsses processos quase 'sub espécie aeternitatis', mas não num prazo adequado para o estudo de tais problemas (destaque nosso). Quem sabe se no ano de 1999 ou de 2459, os Fulniô e outras tribos não continuarāo ainda obstando a uma "homogeneidade de desenvolvimento" da "sociedade nacional", ainda que, pelo seu número, constituíssem obstáculos insignificantes? Em todo caso Darcy Ribeiro poderia aparecer como o herdeiro mais ou menos modernizado da mentalidade imperialista portuguesa se as suas últimas publicações não nos ensinassem, felizmente, o contrário". Evidentemente a critica de Baldus a Ribeiro, neste episódio, é séria e indica claramente divergência de orientaçōes teóricas e de perspectivas na percepção do processo em curso nas relaçōes sociais entre sociedades indigenas e a sociedade nacional.
Baldus era irônico e tinha seus momentos de amenidades, como se pode perceber no episódio que narra em seu Tapirapé: Tribo tupi no Brasil Central (1970: 277/8), envolvendo ele próprio e Charles Wagley; "Parece que os Tapirapé acreditam em concepção mágica, embora saibam ser a gravidez consequência das relaçōes sexuais. Em 31 de março de 1942 contou-me o Dr. Wagley o seguinte: Nos primeiros tempos em que esteve em Tapiitaua, ouviu de repente: "Lá vem Dotoi". Sabia que era êste o nome com que as mulheres e crianças da aldeia costumavam me tratar, acrescentando o diminutivo " $\mathrm{i}$ " ao título pelo qual o camarada Daniel me chamava. Wagley, surprêso, virou-se e viu aproximar-se não o colega de São Paulo, mas um menino tapirapé. "Onde está Dotoi?" perguntou. Indicaram-lhe o menino. "Mas Dotoi está longe", objetou. Então ensinaram-lhe que o menino também se chamava Dotoi, por ser filho do Dotoi de São Paulo. E como prova dessa relação de parentesco mostraram ao etnólogo que o menino, como seu longínquo genitor, não tinha buraco no lábio inferior para o uso do tembetá, como se vê nos meninos tapirapé da sua idade. Numa obra cientificamente sêca como esta, não é preciso tomar em consideração o que Wagley pensou de mim e se êle comparou a côr da pele do Dotoi II com a das outras crianças ao redor. Basta dizer que êle é meu amigo e o norte-americano mais compreensivo que conheço. Naturalmente não deixou de perceber que a idade do menino correspondia mais ou menos ao número de anos passados desde a minha estada em Tampiitaua. Verificou também que Vuanomanchí estava desempenhando o papel de pai do rapazinho. E Vuanomanchi tinha sido meu amigo intimo, em 1935." A par do insólito e do pitoresco da narrativa (que remete, também, às situações embaraçosas em que um etnólogo pode ver-se envolvido, involuntariamente), o trecho citado exibe, em poucas palavras, o dominio da técnica literária e da lingua portuguesa a que chegou o alemāo de nascimento Baldus.

Em 1961, Baldus assumiu a cadeira de Etnologia Brasileira, na Faculdade de Filosofia, Ciências e Letras de Rio Claro, no interior do Estado de São Paulo.

A propósito do $65^{\circ}$ aniversário de nascimento de Herbert Baldus, Hans Becher editou um volume comemorativo de Völkerkundliche 
SAMPAIO-SILVA, O. Herbert Baldus: vida e obra - Introdução ao indigenismo de um americanista teuto-brasileiro. Rev. do Museu de Arqueologia e Etnologia. S. Paulo, 2:91-114, 1992.

Abhandlungen - "Beiträge zur Völkerkunde Südamerikas" (Festgabe für Herbert Baldus zum 65. Geburtstag), em Hannover, no qual trinta especialistas em assuntos Americanistas compartilham com textos de autoria de cada um, para, nesta edição (1964), homenagear o ilustre aniversariante. ${ }^{5}$

(5) Aparecem nesta publicação, os seguintes autores e respectivos títulos: Josef Haekel (Viena) - “Zum Geleit"; Hans Becher (Hannover) - "Carl Richards ethnographische Beobachtungen in Venezuela im Jahre 1820"; Robert L. Carneiro (New York) - "Shifting Cultivation among the Amahuaca of Eastem Peru"; José V. Cesar (Bosieux, Suiça) - "Igaçaba"; William H. Crocker (Washington) - "Extramarital Sexual Practices of the Hamkokamekra-Canela Indians"; Hans Dietschy (Basel) — "Altersstufen bei Karaja Indianern Zentralbrasiliens"; Gertrude E. Dole (New York) - "Shamanism and Political Control among the Kuikuru"; Leo Fainberg (Moscou) - "Überlebsel der matrilinearen Gens bei den Indianern am oberen Xingú”; Florestan Fernandes (São Paulo) - "Aspectos da Educação na Sociedade Tupinambá"; Protásio Frikel (Belém, Pará); "Das Problem der Pianokotó-Tiriyó"; Helmut Fuchs (Caracas) - "Der amoahasó der Deukwhuana (Makiritare) und seine Bedeutung"; René Fuerst (Genebra) - "La peinture collective des femmes Xikrin (Contribution à l"étude des Indiens Kayapo du Brésil Central)"; Eduardo Galvão e Mário F. Simões (Belém, Pará) - "Kulturwandel und Stammesüberleben am oberen Xingú, Zentralbrasilien"; Martin Gusinde (St. Gabriel, Mödling bei Wien) - "Die Religion der Selk'nam auf Feuerland-Entgegnung auf Paul Radin"; Karin Hissink (Frankfurt Main) - "Heilmittel und Heilmethoden bei den Tacana-Indianern"; Cestmir Loukotka (Praga) - "Alguns suplementos ao trabalho "Culturas e linguas indigenas do Brasil"; Anton Lukesch (Graz) - "Indianische Persönlichkeit bei dem Gé-Volk der Kayapó”; Betty J. Meggers and Clifford Evans (Washington) - "Genealogical and Demographic Information on the Wai Wai of British Guiana"; Nobue Myazaki (Marilia, São Paulo) - "Breves Notas sobre a Socialização da Criança em duas Tribos Aruake"; Taryo Obayashi (Tokio) - "Bemerkungen zum Grabstock der Chavante"; Roberto Cardoso de Oliveira (Rio de Janeiro) - "Totemismo Tukuna?"; Donald Pierson (U.S.A.) "Life in a Brazilian Village"; Stig Ryden (Stockolmo) "Tripod Ceramics and Grater Bowls from Mojos, Bolivia"; Wilhelm Saake (St. Augustin bei Bonn) - "Erziehungsformen bei den Baniwa"; Egon Schaden (São Paulo) - "Ethnographische Notizen zu einem ChichaTanzlied der Kayová"; Hermann Trimborn (Bonn) "Cerro de las Rueditas"; Henry Wassen (Gotemburgo) "Un Indio Cuna de Panamá en misión etnografica al Rio Caimán, Colombia, en 1961"; Ursula Wiesemann (Rio de Janeiro) - "Phonological Syllables and Words in Kain-
Herbert Baldus foi um estudioso especialmente interessado na cultura material dos povos indigenas: sua obra está permeada, em muitos momentos importantes, por abordagens da produção ergológica dos indios. Exemplo caracteristico, no qual Baldus demonstra-se profundamente tocado pela arte pictórica indigena, encontra-se em seu substancioso ensaio "Os carimbos dos indios do Brasil" (1961/2). Neste trabalho, Baldus fundamentando-se em pesquisas realizadas por diversos etnólogos, tais como Nordenskiöld, Linné, Koch-Grünberg, D. Ribeiro, Krause, V. Chiara, Métraux, Nimuendajú, Schaden, P. Frikel, Loureiro Fernandes, Crocker, Maybury-Lewis, Albisetti e Venturelli, Galvão, Meggers e Evans, Schultz e outros, faz um extenso estudo objetivando atingir uma sintese sistematizadora dos conhecimentos acumulados sobe estes instrumentos de produção artística indígena. Com base, principalmente, em trabalhos publicados por aqueles autores, em depoimentos pessoais e mesmo em correspondências trocadas com alguns deles $e$, secundariamente, em sua experiência de campo, Baldus registra os diferentes tipos de carimbos produzidos por sociedades indigenas atuais (Mbayá-Guaikurú, Karajá, "Kayapó”, Mayongong, Palikúr, Aparaí, Guarani, Kaingang, Rankókamekra-Canela, Krahó, Apinayé, Xerénte, Bororo, Tiriyó, Kaxúyana e Amahuáka), bem como, de restos arqueológicos (Tupinambá, Marajoara, Tarumá e Manacapurú). Descreve os objetos (muitos dos quais se encontram em museus de diferentes paises do mundo), tenta uma classificação tipológica, tomando como referência a proposta de "áreas culturais indigenas", de Galvão, e registra problemas etnográficos e etnológicos pendentes, como sugestōes para novas pesquisas. $O$ trabalho é enriquecido com abundantes ilustrações constantes de desenhos e fotos de carimbos de diferentes ti-

gáng"; Emilio Willems (Nashville) - "San Andrés: Continuity and Change in the Culture of a Caribbean Island"; Ingrid Wustmann (Leipzig) - “Zur Bedeutung und Verwendung des indianischen Farbstoffe Urucú" - Com um prefácio de Eva LIPS (Leipzig); Otto Zerries (Munique) - "Ausgewählte Holzschnitzarbeiten der BrasilienSammlung Spix und Martius von 1817/20 im Völkerkunde-Museum zu München". 
SAMPAIO-SILVA, O. Herbert Baldus: vida e obra - Introduçào ao indigenismo de um americanista teuto-brasileiro. Rev. do Museu de Arqueologia e Emologia. S. Paulo, 2:91-114, 1992.

pos, bem como de fotos de cenas de carimbagens, além de extensa bibliografia. ${ }^{6}$

$\mathrm{O}$ artigo sobre o xamanismo publicado por Baldus na Revista do Museu Paulista $(1965 / 6)$ é de excelente qualidade cientifica. Trata-se de um trabalho teórico praticamente único na bibliografia etnológica brasileira, de uma abordagem não especificamente sobre esta instituição em uma sociedade determinada, mas sim, um estudo amplo, aberto, geral, com predominante fundamentação bibliográfica em autores expressivos, que se dedicaram a este tema, contendo, também, contribuiçōes pessoais do autor, no sentido de que se baseia, ao lado das demais fontes, em suas observaçōes diretas no campo. A medida em que o texto avança, Baldus insere, em um crescendo, suas interpretações pessoais do ponto de vista teórico, sobretudo nos itens referentes ao xamã e o grupo social (a instituição, o status e a ambivalência).

Como se constata, esse autor versátil e de grande produtividade, teve a publicação de sua obra cientifica marcada por alguns eventos principais, tais como:

1 - a publicação, em 1931 , de sua primeira destacada obra cientifica, o livro Indianerstudien im nordwestlichen Chaco (230 págs.), na qual faz estudos comparativos sincrônicos entre os grupos indígenas Chamacoco e Kaskihá, bem como com os Mbiá, de Mato Grosso;

2 -a publicação dos Ensaios de Etnologia Brasileira (346 págs.) em 1937, reunindo importantes trabalhos seus sobre diferentes grupos indigenas, tais como os Bororo, os Teréna, os Kaingang, os Guayaki, os Karajá, os Tapirapé;

3 - a publicação da Bibliografia Crítica da Etnologia Brasileira, em 1954 (1ำ volume) e em 1968 ( $2^{\circ}$ volume), e

4 - a publicação, já próximo a sua morte, do livro Tapirapé: tribo tupi do Brasil Central (511 págs.).

Nos Ensaios de Etnologia Brasileira, estuda temas sociais variados, com ênfase nas abordagens de religião, e também desenvolve,

(6) A propósito desse ensaio, Melatti (1970:149) comenta: "Herbert Baldus oferece um exaustivo estudo dos carimbos utilizados pelos indios do Brasil, tendo elaborado mesmo uma tipologia". com evidente interesse didático, itens teóricos de grande interesse. "Que é etnologia?" - e responde - "Literalmente: a ciência do povo ou dos povos, isto é, a ciência que estuda as diversas modalidades totais de um povo e suas relaçōes com as modalidades de outros povos. A palavra povo significa, aqui, unidade cultural. Assim, a etnologia estuda a unidade cultural no que diz respeito à sua singularidade local e temporal e às suas relaçōes com outras unidades culturais. A etnologia limita-se ao estudo das chamadas culturas primitivas, por ser ainda uma ciência em formação" (p. 17). Trata-se de um ensaio de caráter préliminar, no qual o autor desenvolve, sinteticamente, conceitos teóricos, como o acima, ainda de orientação fortemente culturalista, da mesma forma como em sua definição de cultura: "Cultura, no sentido que lhe dão os etnólogos, é a expressão harmônica total do sentir, pensar, querer, poder, agir e reagir de uma unidade social, expressão essa que nasce de uma combinação de fatores hereditários, físicos e psiquicos, com fatores coletivos morais, e que, unida ao equipamento civilizador (instrumentos, armas, etc.) dá à unidade social a capacidade $\mathbf{e}$ a independência necessárias à luta material e espiritual pela vida. Um dos problemas principais da etnologia é estudar a mudança contínua desta expressão e as causas dessa mudança" (p. 17). Estabelece as diferenças conceituais entre etnologia e antropologia ("Ciências auxiliares uma da outra", p. 18), entre etnologia e etnografia e sentencia: "o etnólogo será sempre etnógrafo; e o etnógrafo não poderia, sem conhecimento etnológico, fazer trabalho útil" (p. 19). "Ambas as ciências são empíricas e indutivas" (p. 19). Quanto ao livro como um todo, esclarece: "Intitulei o presente livro Ensaios de Etnologia Brasilei$r a$, embora ele tenha, na maior parte, caráter puramente etnográfico. Mas esse material etnográfico serve, principalmente, para estudar um problema etnológico, qual seja a mudança de cultura entre indios no Brasil" (p. 19). ${ }^{7} \mathrm{E}$

(7) A propósito desse interesse teórico especifico encontrado nas obras de Baldus, Galvão (1979:127) faz o seguinte comentário, agrupando o nosso autor com outros antropólogos que considera participantes da mesma linha teórica em Antropologia, entre os quais ele próprio: “Repetiriamos na prática a comunicação do professor Baldus, pois nos trabalhos mais recentes, a partir de Nimuendajú 
o autor indaga: "E por que estudamos etnologia? Estudamos os chamados povos primitivos para, com base nos conhecimentos assim adquiridos, poder estudar melhor os povos chamados de alta cultura" (p. 20), atribuindo, dessa maneira, um caráter instrumental à etnologia que, segundo essa concepção, atua como vetor para estudos que Baldus considerava, à época, que estavam fora de seu campo especifico de abordagem.

Neste mesmo ensaio (Etnologia Brasileira), Baldus faz especialmente critica à posição da Igreja face aos índios, nos primeiros tempos de colonização: "Era mais cômodo, para os cristão que avançavam apresentar esses povos estranhos (povos periféricos, povos não cristão) como seres de ordem inferior, para melhor explorá-los, combatê-los e subjugá-los. No ano de 1537, o papa Paulo III declarava numa bula que os indios eram homens. Semelhantes deliberaçōes eram tomadas, em parte, para privar os colonos europeus dos trabalhadores indígenas e aproveitá-los, economicamente, só para a Igreja. Os célebres defensores da liberdade do indio, como, por exemplo, o bispo Las Casas, não se opuseram à importação de escravos africanos para a América" (p. 21). Imprimindo essa orientação analítica e interpretativa, Baldus, já em 1937, fazia florescer um tipo de abordagem histórica dialética, que só anos mais tarde viria a tornar-se corrente nos estudos etno-histuricos, que se desenvolveram no Brasil, tendo sido este mais um dos setores científicos, em nosso pais, atingidos pelo pioneirismo do autor. Neste mesmo livro, Baldus oferece abundantes dados etnográficos sobre o culto aos mortos pelos indios Kaingang (pp. 19/69); desenvolve amplo estudo sobre a posição social da mulher entre os Bororo Orientais (pp. 112/62); além de outros temas importantes, retoma o estudo da mudança de cultura em sociedades indígenas (pp. 187/275). No ensaio sobre a posiçāo so-

e desse etnólogo, seguindo com os de Wagley, Schaden, Watson, Oberg, Altenfelder Silva, Ribeiro, Galvão, Murphy e Hohenthal, mesmo se não trazem, como acontece em sua maioria, definido em título principal ou subtítulo o tema aculturação, constituem, todos eles, análises de culturas indigenas em transiçāo, e em que o principal fator de mudança deriva de uma situação de contacto com populaçōes rurais brasileiras". cial da mulher, faz descrições do meio ambiente, bem como, físicas dos indios estudados, suas vestimentas, adornos pessoais, e sua alimentação; reitera a informação de que "entre quase todos os povos primitivos da América do Sul é a mulher que leva a carga durante as marchas, enquanto o homem só anda com as armas na mão" (p. 118). Discorda de que por esta razão seja "oprimida ou escrava", como a consideram viajantes apressados e missionários católicos (cf. suas palavras). No bojo desse ensaio, aborda temas tais como o parto e a colaboração do homem; o couvade; diferentes meios abortivos; restrições ("resguardo") da mãe; o infanticidio ("Entre os Bororo estas causas de infanticídio - são disfarçadas pela crença que estabelece uma conexão entre a criança esperada e ainda não nascida e os maus sonhos de um dos parentes e especialmente da própria futura mãe", p. 121); iniciaçōes de jovens; menstruação; divisão de trabalho por sexo ("a criança, nos primeiros anos é guardada pela mãe", p. 129); metades exogâmicas; casamento; organização matrilinear; vida sexual (refere que a monogamia predomina; que "a homossexualidade e o onanismo sāo desconhecidos entre os Bororo, como entre a maior parte das tribos de índios visitados por mim", p. 146; que "ambos os sexos não guardam severamente a fidelidade conjugal", p. 149); que há ciúme e ocorrem brigas, duelos entre mulheres por ciúme; os mexericos entre mulheres, de umas em relação às outras; a participação em cantos e danças por ambos os sexos; a morte; mudanças sócioculturais por influência da sociedade dominante, principalmente dos padres salesianos. Ao desenvolver esse tema, neste ensaio especifico, Baldus reporta-se às mudanças nas culturas materiais e "espirituais" (sic) dos Kaingang, Borôro, Karajá e Tapirapé, e define: “Entendemos por 'mudança de cultura' a alteraçāo na harmônica expressão global de todo o sentir, pensar e querer, poder, agir e reagir de uma unidade social, expressão que nasce de uma combinação de fatores hereditários, físicos e psíquicos, com fatores coletivos morais, e que, unida ao equilibrio civilizador, como, por exemplo, instrumentos, armas, etc., dá à unidade social a capacidade e a independência necessária à luta material $\mathrm{e}$ espiritual pela vida" (p. 276); classifica as 
SAMPAIO-SILVA, O. Herbert Baldus: vida e obra - Introdução ao indigenismo de um americanists teuto-brasileiro. Rev. do Museu de Arqueologia e Etnologia. S. Paulo, 2:91-114, 1992.

causas da mudança de cultura em causas que vêm de "dentro", isto é, da própria unidade cultural, e as que vêm de "fora", ou seja, de outra unidade cultural; porém, trata, no ensaio, apenas das causas originárias de "fora", ou seja, as "influências européias" (p. 306); trata também do espaço de tempo da mudança de cultura, da mudança parcial de cultura e da mudança total de cultura. E Baldus considera as culturas indigenas como subculturas brasileiras (V. Bibliografia Critica da Etnologia Brasileira, Vol. II, 1968, p. 83).

Em Tapirapé: Tribo tupi do Brasil Central, Baldus apresenta, neste que é um complexo trabalho monográfico, suas análises e interpretaçōes das observaçōes realizadas entre os Tapirapé, nas visitas que fez a esse grupo em 1935 e 1947. Trata-se de um estudo exaustivo, no qual estuda os diferentes aspectos desta sociedade e faz comparaçōes desta com a de outros grupos indígenas da área em tomo do rio Araguaia. Traz à sua obra material etnológico propiciado por outros pesquisadores, entre os quais e principalmente, Charles Wagley, do qual apresenta polêmicas discordâncias. Suas discrepâncias com Wagley, jä se haviam evidenciado em outras oportunidades, como, por exemplo, em "Zur Häuptlingsfrage bei den Tapirapé" (1968), no que diz respeito à chefia do grupo Tapirapé.

Baldus elaborou uma obra de grande perenidade, trabalhando, por um lado, com objetivos didáticos, de esquematização e de propiciar conhecimentos e informações, e, por outro, concretizando um grande projeto de documentação sistemática com vistas ao desenvolvimento da pesquisa científica nos campos da etnologia e da etnografia. Aí se inscrevem tanto suas sinopses e resenhas sobre obras e autores nacionais e estrangeiros, que trabalharam no Brasil (V. os dois primeiros volumes da Bibliografia Crítica da Etnologia Brasileira), ${ }^{8}$ como suas reconstituiçōes dos acervos históricos constantes das contribuiçōes aos estudos antropológicos dos grupos indigenas do Brasil dadas por missionários, cronistas, via-

(8) A profa. Thekla Hartmann, seguindo a mesma metodologia de Baldus, deu sequência ao projeto do mestre, no terceiro volume da Bibliografia Crítica da Ernologia Brasileira. jantes, artistas e etnólogos, desde a carta de Pero Vaz de Caminha até nossos dias. Na linha de abordagem dos estudos históricos, 0 "Ensaio sobre a história da Etnologia Brasileira" (1943) é modelar, propiciando indicaçōes fundamentais sobre autores e as características de seus estudos ao longo da história do pais, jả abrindo perspectivas para as abordagens dos grupos indigenas em situação de contato, que viriam a ser o veio principal dos estudos antropológicos brasileiros, sobretudo a partir do inicio da segunda metade deste século. As digreçōes de Baldus, naquele ensaio, abrem caminhos cientificos, que muitos vieram a trilhar. ${ }^{9}$

Em sua obra antropológica volumosa e variada,Baldus usava linguagem clara e direta - conforme preceito de estilistica, para textos científicos - nas formulaçōes das explanaçōes, quer as descritivas, quer as interpretativas das questōes relacionadas com as sociedades indigenas e com a produção cientifica em antropologia. Intelectualmente honesto e autêntico detentor do saber cientifico, Baldus não fazia jogo de palavras vazio e enganador.

Os trabalhos produzidos por Baldus sempre tiveram ampla divulgação, tanto no Brasil quanto no exterior. Há trabalhos de Baldus que, mesmo no Brasil, foram publicados mais de uma vez, além dos que vieram a lume em mais de uma lingua em diversos paises, como no caso de "Ensaios sobre a História da Etnologia Brasileira", que foi publicado em $O E s$ tado de S. Paulo, de 9, 11 e 16/9/43, no Boletim Bibliográfico da Biblioteca Pública Municipal de São Paulo, I, 1943, e no Manual Bibliográfico de Estudos Brasileiros, Rio de Janeiro, 1949, além de, ampliado, voltar a aparecer na Introdução ao primeiro volume da Bibliografia Crítica da Etnologia Brasileira, 1954 (em português), tendo, também, sido pu-

(9) Roberto Cardoso de Oliveria (1964:26-27), referindose a Baldus, entre outros, faz a seguinte observação: "Essa preocupação sobre o destino das populaçōes tribais é uma constante na etnologia brasileira, desde os trabalhos de Nimuendajú e Baldus, até Schaden, Galvão e Darcy Ribeiro. $O$ enraizamento de todos eles à realidade nacional - e não apenas indigena - permitu-lhes, de certo modo, repensar os problemas colocados pelas teorias de aculturação, caracteristicamente descomprometidas com a sobrevivência das populaçōes tribais". 
SAMPAIO-SILVA, O. Herbert Baldus: vida e obra - Introdução ao indigenismo de um americanista teuto-brasileiro. Rev. do Museu de Arqueologia e Etnologia. S. Paulo, 2:91-114, 1992.

blicado, em espanhol, na Revista Mexicana de Sociologia, V, n² 2, México, 1943. Muitos de seus trabalhos, sobretudo os primeiros, foram publicados em alemão, como no caso do ensaio: "Die Allmutter in der Mythologie zweier südamerikanischer Indianerstämme", que saiu no Archiv für Religionswissenschafi, XXIX, Leipzig, em 1932, tendo sido traduzido para o francês por Alfred Métraux e publicado na Revista del Instituto de Etnologia, II Tucumán, $1932 .{ }^{10}$

Predominam, na obra de Baldus, as abordagens dos temas sociais a partir da análise de dados empíricos da realidade, o que não o levou a omitir-se quanto aos estudos teóricos. Em seu artigo entitulado "Difusionismo, Concentrismo e Funcionalismo" , com muita clareza, desenvolve, inicialmente, uma explanação crítica em torno do difusionismo, sobre as contribuições de Lafitau, Ratzel, Frobenius, Schimidt, além de outros; método a que denomina de concentrismo "para frisar o contraste com o difusionismo", cf. suas palavras -, e, do funcionalismo, já enfatizando a importância das "relaçōes estruturais". Ao analisar o difusionismo, sua crítica passa pelos conceitos de "ciclos culturais" e de "áreas culturais" (cf. Boas, Waissler, Kroeber) e extravasa consideraçōes lúcidas, tais como quando diz: "Por ignorar as relaçōes estruturais e funcionais que os traços estudados têm em sua cultura, seu valor para a compreensão da cultura é secundário, pois os difusionistas nāo conseguem senão formar hipóteses sobre migrações e processos de transferências. Indubitavelmente, foi imenso o número destes processos, no mundo inteiro. Levando-se em consideração a abundância de alteraçōes e de transformaçōes operadas na maioria dos fenômenos culturais, evidencia-se o fato de só podermos constatar a sua transferência local ou temporal, quando conservam a sua forma de modo reconhecivel. Esta conservação se dá, porém, só em número reduzido de casos. É por isso que uma teoria como o difusionismo, que considera esse número restrito de transferências como objeto de investigação, não poderá

(10) Este mesmo artigo aparece na bibliografia de Baldus - levantada no decorrer deste estudo -, traduzido para o português pelo autor deste ensaio. desempenhar um papel decisivo na Etnologia" (p. 130). Tendo o trabalho em foco vindo a lume em 1941, Baldus, então, ainda podia referir-se a que os métodos norte-americanos da "áreas culturais" ainda nāo haviam sido "realizados, que eu saiba, no Brasil..." (p. 131). A proposta de "áreas culturais indígenas", de Eduardo Galvão, só seria publicada em 1960 (Galvão, 1960). Para caracterizar o "concentrismo", Baldus diz que esse método "naturalmente, aproveita também qualquer oportunidade para verificar, deste modo, uma transferência. Mas considera os parentescos culturais como problema secundário, pois encara, em primeiro lugar, a concentração e não a difusão dos elementos culturais,quer dizer, a sua integração em uma determinada cultura e não a sua expansão pelo espaço e tempo" (p. 131). Aponta KochGrünberg como um dos pesquisadores que trabalham com "métodos concentristas", no Brasil. No mesmo ensaio, Baldus refere-se a Bastian que, conforme sua interpretação, estudou o fato cultural como objeto psicológico e desenvolveu a teoria das "idéias-de-povo" (Völkergedanken), lançando a semente do funcionalismo. Destaca, na escola funcionalista, os etnólogos Radcliffe-Brawn (que realizou o "estudo das designações de parentesco em conjunto com os deveres, direitos e outras funçōes - sociais - de seus portadores", cf. Mühlmann, cit. por Baldus), Thurnwald ${ }^{11}$ e Malinowski. No final do trabalho, Baldus, sempre animado a contribuir para o melhor desempenho de nossos etnólogos no campo, delineia orientações metodológicas da maior utilidade para a prática da pesquisa antropológica, apresentadas em linguagem cristalina, dando ênfase à necessidade de o pesquisador, no campo, procurar

(11) "Tomemos como ponto de referência antigos cursos de Lévi-Strauss e de Herbert Baldus: o primeiro dava grande atençào às possibilidades teóricas de descrição das comunidades humanas $\mathrm{e}$ às diretrizes metodológicas em que elas repousavam, procurando descobrir em que consistia a contribuição positiva e as limitaçōes de cada uma delas; o segundo, como antigo aluno de Thumwald, nunca defendeu intransigentemente o funcionalismo, esforçando-se, ao contrário, para pôr em evidência as vantagens $e$ as desvantagens de outras orientaçōes metodológicas, como a "concentrista" e a "difusionista", no estudo de comunidades indigenas brsileiras." (Fernandes, 1975:135). 
SAMPAIO-SILVA, O. Herbert Baldus: vida e obra - Introdução ao indigenismo de um americanista teuto-brasileiro. Rev. do Museu de Arqueologia e Etnologia. S. Paulo, 2:91-114, 1992.

assumir diferentes papéis, face a seu objeto de estudo, tendo em vista atingir a maior objetividade, como um experimentador, conforme se lê em stas palavras; "O etnólogo, ao assumir o papel de Vaz de Caminha, deve estar consciente de sua condição como experimentador, o qual,por ser componente integrante de sua própria experiência, precisa ser tomado em consideração tanto como seu objeto. Conseguindo o etnólogo esse reconhecimento bilateral, no qual encara a interação entre si mesmo como experimentador e o objeto, conseguindo, assim, o que chamamos ganhar distância de si mesmo, aproxima-se, cada vez mais, da objetividade" (p. 139).12

A experiência militar do jovem Baldus, na guerra, em seu pais de origem, não moldou sua personalidade e seu comportamento político. Baldus foi um antiprussiano por excelência, um pacifista antinazista, um liberal progressista, um democrata convicto, um humanista empolgado pela causa da sobrevivência dos povos indigenas. ${ }^{13}$ Com o advento de sua morte, alguns de seus amigos e/ou discipulos fizeram publicar artigos em sua homenagem, tais como: "Hommage à Herberi Baldus (18991970)", por René Fuerst; 14 "Herbert Baldus -

(12) “Algumas das principais criticas à problemática $e$ às tendências teóricas dos estudos brasileiros de etnologia e sociologia foram formuladas em A Etnologia e a Sociologia no Brasil, de Florestan Fernandes. Essas reflexōes, associadas com os artigos e ensaios de Herbert Baldus, Egon Schaden, Charles Wagley, Marvin Harris, Thales de Azevedo e outros, oferecem um quadro bastante amplo sobre a formação geral e os aspectos particulares das pesquisas etnológcias e sociológicas no Brasil” (Ianni, 1966:24).

(13) “Na geração dos pais fundadores (o autor refere-se aos fundadores do que chama de 'nossa familia de etnologos brasileiros'), temos três figuras esplêndidas: Herbert Baldus, poeta-cientista, teutònico, mulherengo, prussiano, romântico e antifacista. Foi quem nos trouxe as luzes de Thurnwald, que nos livraram de tanta tolice norte-americana; mas foi principalmente quem nos tangeu para o estudo dos indios lá nos matos onde eles viviam. A ele devemos também haver organizado criticamente a bibliografia etnológica brasileira, desmonopolizando a informação livresca que tantos tolos, anteriormente, em seu primarismo, escamoteavam e escondiam." ("Prefácio" de Darcy Ribeiro ao Encontro de Sociedades, 1979, de E. Galvão).

(14) "Avec la mort du professeur Herbert Baldus, les derniers indiens du Brésil ont perdu l'un de leurs plus grands
1899-1970", por Hans Becher; ${ }^{15}$ o editorial "Herbert Baldus - In Memoriam", in Anais do Museu de Antropologia, da Universidade Federal de Santa Catarina, ${ }^{16}$ e o editorial da Revista do Museu Paulista, sob o título "Herbert Baldus (1899/1970)". ${ }^{17} \mathrm{Na}$ oportunidade do $10^{\circ}$ aniversário do falecimento de Herbert Baldus, o eminente etnólogo foi homenageado no evento promovido em sua memória, na Escola de Sociologia e Política de São Paulo, patrocinado por esta Escola e pelo Museu Paulista da Universidade de São Paulo: ${ }^{18}$

Relatar a volumosa e polivalente obra de Herbert Baldus é uma tarefa extremamente complexa, não apenas devido ao grande número de trabalhos produzidos, ao longo de $\mathbf{5 0}$ anos de ação cientifica, mas, principalmente, pela variedade dos temas desenvolvidos, comprometidos com tantas ảreas das ciências sociais. Seu saber cientifico, à medida em que ia sendo concebido, como fruto de seu traba-

connaisseurs et plus sincères défenseurs, la science américaniste l'un de seus meilleurs chercheurs, notre Société l'un de ses plus illustres membres et moi-même un ami dont l'exemple, l'impulsion et la critique ont contribué au déroulement de ma modeste carrière" (Fuerst, 1971: 35-36).

(15) "Through Herbert Baldus, São Paulo became the undisputed heart of Americanistic research in South America, for he was the first to systematize the studies of South American ethnology“ (Becher, 1972:1307-12).

(16)"Baldus nāo apenas descrevia e interpretava fatos das culturas primitivas em face da sociedade nacional envolvente, mas preocupava-se constantemente pelo futuro dessas populaçōes. Prova disso são os muitos artigos e conferências que deixou sobre politica indigenista no Brasil" (Editorial "Herbert Baldus - In Memoriam", 1971:144-145).

(17) “Alemão de nascimento, Herbert Baldus continuou em nossos dias, como já se escreveu, tôda uma tradição cientifica de raizes germânicas voltadas para as culturas indigenas sulamericanas, tradição que vai de Martius a Kurt Nimuendajú, por ele continuada sob um enfoque tipicamente brasileiro, aperfeiçoando dessa perspectiva as rotas pioneiras de um Couto de Magalhães ou de um Teododro Sampaio" ("Herbert Baldus (1899/1970)", 1968/ 69:7).

(18) Evento realizado a 24-10-1980. Nesta oportunidade, em texto produzido por Charles Wagley, este antropólogo depōe: "Herbert Baldus e eu estávamos ligados um ao outro durante mais de 30 anos pelo interesse que ambos mantinhamos pelo indio brasileiro e mais especificamente pelos estudos sobre uma pequena tribo: os Tapirapé do Brasil Central"- (Gainesville, outubro/1980). 
SAMPAIO-SILVA, O. Herbert Baldus: vida e obra - Introduçào ao indigenismo de um americanista teuto-brasileiro. Rev. do Museu de Arqueologia e Etnologia. S. Paulo, 2:91-114, 1992.

lho diuturno no campo, nas bibliotecas e em seu gabinete, era divulgado através de periódicos e de livros, incessantemente publicados. Desta obra e de sua vida, da qual é fruto, oferece-se uma sintese ilustrativa e representativa, neste ensaio. Sua obra cientifica se ca- taloga em diferentes campos da antropologia, exprimindo a elaboração do conhecimento científico ao longo da vida, que se caracterizou pela laboriosa ação de documentação das sociedades e culturas indigenas e pela luta em sua defesa.

SAMPAIO-SILVA, O. Herbert Baldus: life and work - Introduction to the Indigenism of a German-Brazilian americanist Rev. do Museu de Arqueologia e Etnologia S. Paulo, 2:91-114,1992.

ABSTRACT: Herbert Baldus was a German-Brazilian anthropologist who played an important role in the development of anthropological research and knowledge in Brazil. His scientific work was intimately linked to his own life, spent mostly in this country, where he devoted himself to teaching, to research and scientific divulgation, as well as to the establishment of an official Indian policy bent on the preservation of ethnic populations. His theoretical contributions ranged from initial investigations on material and non-material culture to functional and structural approaches, while he also established the foundations for the study of cultural change of Indian societies in contact situations.

\footnotetext{
UNITERMS: Life - Work - Indigenism - Preservationism Contact situation - Cultural change.
}

\section{Referências bibliográficas}

BECHER, H. Herbert Baldus - 1899-1970. American Anthopologist, 74, no5, 1972.

EDITORIAL "Herbert Baldus (1899-1970)". Rev do Museu Paulista, N.S., Vol. XVIII, 1968/69.

EDITORIAL "Herbert Baldus - In Memoriam". Anais do Museu de Antropologia da Universidade Federal de Santa Catarina, Ano IV, no 4, 1971.

FERNANDES, F. Investigą̧ão Etnológica no Brasil e outros ensaios, Ed. Vozes, Petrópolis, 1975.

FUERST, R. Hommage à Herbert Baldus. Bulletin de la Societé Suisse des Americanistes, $\mathrm{n}^{\circ}$ 35, 1971.

GALVÃO, E. Áreas culturais indígenas do Brasil: 1900-1959. Boletim do Museu Paraense "Emilio Goeldi", Antropologia, n 8, Belém, 1960.
—.Encontro de Sociedades, Ed. Paz e Terra, Rio de Janeiro, 1979.

IANNI, O. Raças e Classes Sociais no Brasil, Ed. Civilização Brasileira, Rio de Janeiro, 1966.

MELATTI, J.C. Índios do Brasil, Coordenada Editora de Brasilia, Brasilia, 1970.

OLIVEIRA, R. Cardoso de. O Índio e o mundo dos brancos, Ed. Dif. Européia do Livro, São Paulo, 1964.

SOUZA, C.C. O método Rorschach aplicado a um grupo de indios Kaingang. Revista do Museu Paulista, N.S., Vol. VII, São Paulo, 1953.

WAGLEY, C. "Herbert Baldus: In Memoriam" University of Florida, Gainsville, Florida, 1980. 
SAMPAIO-SILVA, O. Herbert Baldus: vida e obra - Introdução ao indigenismo de um americanista teuto-brasileiro. Rev. do Museu de Arqueologia e Etnologia. S. Paulo, 2:91-114, 1992.

\section{Bibliografia de Herbert Baldus*}

“Eduard Hörhan”. Germania. Wochenbeilage zur Deutschen Zeitung, 47. Jahrgang, n. 38, S. Paulo, 18-9-1925.

“Os indios Chamacoco". Revista do Museu Paulista, $X V$, S.Paulo, 1927.

"Ligeiras notas sobre os indios Guaranys do litoral paulista". Revista do Museu Paulista, XVI, S. Paulo, 1929. (1)

“Beim Oberhäuptling der Kaskihá-Indianer":. Der Erdball, IV, Berlin, 1930.

"Notas complementares sobre os indios Chamacoco". Revista do Museu Paulista, XVII, S. Paulo, 1931.

"Kaskihá-Vokabular". Anthropos, XXVI, Viena, 1931.

"Ein Tag der Tumerehá-Indianer". Der Erdball, $V$, Berlin, 1931.

Indianerstudien in nordöstlichen Chaco. Forschungen zur Völkerpsychologie und Soziologie, XI, Leipzig 1931. (2)

"Die Allmutter in der Mytologie zweier südamerikanischer Indianerstämmen. Achiv für Religionswissenschaft, XXIX, Leipzig, 1932. (3)

"Njandutti". Welt und Wissen, XXI, Berlin, 1932.

“Erland Nordenskiöld". Sociologus, VIII, Leipzig, 1932.

"Beiträge zur Sprachenkunde der Samuku-Gruppe". Anthropos XXVII, Viena, 1932.

"Völksüberlieferungen aus Paraguay. Die Geschichten von Pora und Pombero". Der Weltkreis, III, Berlin, 1933.

“Meine Forschungsreise im östlichen Südamerika”. Anthropos, XXIX, Viena, 1934.

"Die Erbfolge der Häuptlinge bei den Tereno". Eth nologischer Anzeiger, IV, Stuttgart, 1935. (4)

"Sprachproben des Kaingang von Palmas". Anthropos, XXX, Viena, 1935.

"Ligeiras notas sobre os idios Tapirapés". Revista do Arquivo Municipal, XVI, S. Paulo, 1935.

"Conceito moderno de etnologia". Revista do Arquivo Municipal, XVIII, S. Paulo, 1935.

"Ligeiras notas sobre duas tribos Tupis da margem paraguaia do alto Paraná”. Revista do Museu Paulista, XX, S. Paulo, 1936. (5)

"Licocós". Espelho, n. 21, Rio de Janeiro, 1936.

Ensaios de Etnologia Brasileira. Biblioteca Pedagógica Brasileira. Brasiliana, Cia. Ed. Nacional, S. Paulo, 1937. (6)

"Tereno-Texte". Anthropos, XXXII, Viena, 137. (7)

"As pinturas rupestres de Sant Ana da Chapada (Mato Grosso)". Revista do Arquivo Municipal, XL, S. Paulo, 1937.

"Kulturwandel bei Indianern in Brasilien". Archiv für Anthropologie und Volkerforschung, N.F., Bd XXIV, Heft 3/4, Braunschweig, 1938. (8)

(*) Acompanha esta bibliografia uma série de notas explicativas arroladas nas páginas subsequentes.
"Uma ponte etnográfica entre o Xingú e o Araguaia". Revista do Arquivo Municipal, XLIII, S. Paulo, 1938.

“Die Doppelfolge". Archiv für Anthropologie und Volkerforschung, N.F., Bd. XXIV, Heft 3/4, Braunschweig, 1938. (9)

"A obra de Karl von den Steinen". Revista do Arquivo Municipal, L, S. Paulo, 1938.

Dicionário de Etnologia e Sociologia (em coautoria com Emilio Willems). Biblioteca Pedagógica Brasileira, série 4a. Iniciaçāo Cientifica, vol. 17, $\mathrm{S}$. Paulo, 1939. (10)

"A necessidade do trabalho indianista no Brasil". Revista do Arquivo Municipal, LVI, S. Paulo, 1939. (11)

"Herrschaftsbildung und Schichtung bei Naturvölkern Sudamerikas". Archiv für Anthropologie, Volkerforschung und Kolonialen Kulturwandel, N.F., Bd. XXV, Braunschweig, 1939.

"Instruçōes gerais para pesquisas etnográficas entre os indios do Brasil". Revista do Arquivo Municipal, LXIV, S. Paulo, 1940. (12)

"O conceito do tempo entre os Índios do Brasil". Revista do Arquivo Municipal, LXXI, S. Paulo, 1940.

"Teoria e prática etnológicas". Sociologia, II, n. 4, S. Paulo, 1940. (13)

"Difusionismo, Concentrismo e Funcionalismo". Sociologia, III, n. 2, S. Paulo, 1941.

“Maximiliano Principe de Wied-Neuwied". Revista do Arquivo Municipal, LXXIV, S. Paulo, 1941.

"Casas e túmulos japoneses no vale do Ribeira de Iguape" (em colaboração com Emilio Willems). Revista do Arquivo Municipal, LXXVII, S. Paulo, 1941.

"Aldeia, casa, móveis e utensilios entre os indios do Brasil”. Sociologia, IV, n.2, S. Paulo, 1942.

"Cultural change among Japanese immigrants in Bra-

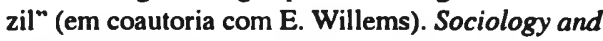
Social Research, XXVI, n. 6, The University of Southern California Press, California, 1942.

"Sinopse de cultura guayaki". Sociologia, V, n. 2, S. Paulo, 1943.

"Ensaio sobre a História da Etnologia Brasileira". Boletim Bibliográfico da Biblioteca Pública Municipal de São Paulo, I, S. Paulo, 1943. (14)

"Novidades Tupinológicas". Boletim Bibliográfico, ano I, vol. IV, S. Paulo, 1944. (15)

"Problemas indigenistas no Brasil". América Indigena, IV, México, 1944.

"Comunicação e comércio entre os indios do Brasil". Sociologia, VI, n. 3, S. Paulo, 1944.

"O rio Tapirapé". Anais do IX Congresso Brasileiro de Geografia, V, Rio de Janeiro, 1944. (16)

“Os Tapirapé, tribo tupi no Brasil Central". Revista do Arquivo Municipal, XCVI, S. Paulo, 1944. (17) (18)

"Franz Boas e a Alemanha". Boletim Bibliográfico, VII, S. Paulo, 1945. (19) 
SAMPAIO-SILVA, O. Herbert Baldus: vida e obra - Introduçào ao indigenismo de um americanista teuto-brasileiro. Rev. do Museu de Arqueologia e Etnologia. S. Paulo, 2:91-114, 1992.

"Curt Nimuendaju". Boletim Bibliográfico, VIII, S. Paulo, 1945. (20)

"Possibilidades de pesquisas etnográficas entre os indios do Brasil". Boletim Bibliográfico, IX, S. Paulo, 1945. (21) (22)

Lendas dos Índios do Brasil. Ed. Brasiliense, S. Paulo, 1946. (23)

"The Guayaki" (em colaboração com A. Métraux). Handbook of South American Indians, I, Washington, 1946

“Almofariz de pedra encontrado no municipio de $\mathrm{Cu}$ nha, Estado de S. Paulo". Revista do Arquivo Municipal. CVII, S. Paulo, 1946. (24)

"Os Tapirapé, tribo tupi no Brasil Central". Revisto do Arquivo Municipal, CVII, S. Paulo, 1946. (25)

“Os Kaingang do Ivai". Revista do Museu Paulista, N.S., I, S. Paulo, 1947.

"Chavante". O Estado de São Paulo, 1 e 4/1, S. Paulo, 1947.

"Cultura material". O Estado de São Paulo, 11 e 18/6, S. Paulo, 1947.

"Voltando do Araguaia". O Estado de São Paulo, 25/10, 5, 7 e 9/11, S. Paulo, 1947.

"Vocabulário zoológico Kaingang". Arquivo do $\mathrm{Mu}$ seu Paranaense, VI, Curitiba, 1947.

"Aplicação do psico-diagnóstico de Rorschach a indios Kaingang" (coautoria com Aniela Ginsberg). Revista do Museu Paulista, N.S., I, S. Paulo, 1947. (26)

"Aquisição de sustento entre os indios do Brasil". Sociologia, X, n. 4, S. Paulo, 1948.

"Fontes primárias para o estudo dos indios do Brasil quinhentista". Publicação do Instituto de Administraçāo, n. 28, S. Paulo, 1948. (27)

"É belicioso o Chavante?". O Estado de São Paulo, $30 / 7$ a 6/8, S. Paulo, 1948. (28)

"Novidades Americanistas". O Estado de São Paulo, 10/10, S. Paulo, 1948.

“Relatório da Secção de Etnologia". Revista do $\mathrm{Mu}$ seu Paulista, N.S., II, S. Paulo, 1948. (29)

"Tribos da bacia do Araguaia e o Serviço de Proteçào aos Indios". Revista do Museu Paulista, N.S., II, S. Paulo, 1948. (30)

"Etno-Sociologia brasileira". Revista do Museu Paulista, N.S., III, S. Paulo, 1949. (31)

“Georg Friederici 1866-1947". Revista do Museu Paulista, N.S., III, S. Paulo, 1949.

"O problema da atração do indigena brasileiro ao contato com o branco". Folha da Manhã, 19/6, S Paulo, 1949. (32)

"Akkulturation im Araguaya - Gebiet". Anthropos XLI-XLIV, Heft 4-6, Freiburg/Schweiz, 1949.

"Novidades americanistas II". O Estado de São Paulo, 7/8, S. Paulo, 1949.

"Sociedade Amigos do Indio". Revista do Arquivo Municipal, CXXVIII, S. Paulo, 1949. (33) (34)

"Kanaschiwuá und der Erwerb des Lichtes. Beitrag zur Mithologie der Karajá-Indianer”. Beiträge zur Gesellungs-und Volkerwissenschaft: Festschrift zum achtezigsten Geburtstag von Professor Richard Thurnwald. Berlim, 1950. (35)
"A alimentaçào dos indios do Brasil". Sociologia, XII, n. 1, S. Paulo, 1950.

“Bebidas e narcóticos dos indios do Brasil". Sociologia, XII, no 2, S. Paulo, 1950.

"Lendas dos Indios Tereno". Revista do Museu Paulista, N.S., IV, S. Paulo, 1950.

"A vida de Arthur Ramos e sua contribuição aos estudos indianistas". Revista do Museu Paulista, N.S., IV, S. Paulo, 1950.

"Um indigenista do Brasil no sudeste norte-americano". América Indígena, XI, n. 1, México, 1951. (36)

"Max Schmidt 1874-1950". Revista do Museu Paulista, N.S., V, S. Paulo, 1951. (37)

"Tonscherbenfunde in Nordparaná". Archiv für Volkerkunde, VLVII, Viena, 1951/52. (38)

“Periódicos etnológicos em lingua alemā”. Boletim Bibliográfico da Biblioteca Pública Municipal de São Paulo, Vol. XX, S. Paulo, 1952. (39)

"Breve noticia sobre os Mbyá-Guarani de Guarita". Revista do Museu Paulista, N.S., VI, S. Paulo, 1952. (40)

"Caracterizaçào da cultura tapirapé". Selected Papers of the XXIXth. International Congress of Americanists, Chicago, 1952.

"Terminologia de parentesco Kaingang". Sociologia, $X I V$, n. 1, S. Paulo, 1952. (41)

"Karajá-Mythem". Tribus: Jahrbuch des LindenmuseuIIs, N.F., IIIIII (1952/53), Stuttgart, 1953.

"Sinópse da História dos Kaingang paulistas". São Paulo em Quatro Séculos, I, Instituto Histórico e Geográfico de Sào Paulo, S. Paulo, 1953. (42) (43)

Bibliografia Critica da Etnologia Brasileira. Comissão do IV Centenário de Sāo Paulo, S. Paulo, 1954 (44)

"Bibliografia Comentada da Etnologia Brasileira (1943-1950)". Série Bibliográfica de Estudos Brasileiros, I, Rio de Janeiro, 1954. (45)

"Richard Thurnwald 1869-1954". Revista de Antropologia, II, n. 1, S. Paulo, 1954.

“Os Oti". Revista do Museu Paulista, N.S., VII, S. Paulo, 1954.

"Kritische Bemerkungen zu einem brasilianischen Thema". Anthropos, XLIX, Freiburg/Schweiz, 1954.

"Publicações sobre os indios do Brasil nos últimos quinze anos (1939-1953)". Sociologia, XVI, n. 1, S. Paulo, 1954. (46)

“Gegenwärtiger Stand der Völkerkunde des SchingúGebietes". Sociologus, N.S., IV, Berlim, 1954. (47).

"Primitivos da Argentina". Anhembi, n. 39, S. Paulo, 1954.

"Supernatural Relations with Animals among Indians of Eastern and Southern Brazil". Proceedings of the Thirtieth International Congress of America nists (Cambridge, 1952), Londres, 1954. (48)

"O estudo etnográfico do indio no Brasil". Revista do Museu Paulista, N.S., IX, S. Paulo, 1955. (49)

“As danças dos Tapirapé". Anais do XXXI Congresso Internacional de Americanistas (São Paulo, 1954), I, S. Paulo, 1955. 
SAMPAIO-SILVA, O. Herbert Baldus: vida e obra - Introdução ao indigenismo de um americanista teuto-brasileiro. Rev. do Museu de Arqueologia e Etnologia. S. Paulo, 2:91-114, 1992.

"Das Dualsystem der Kaingang-Indianer". Actes du IV Congrès International des Sciences Anthropologiques et Ethnologiques (Vienne, 1952), II, Viena, 1955. (50)

"Ethnologische und linguistische Forschungsaufgaben in Brasilien". Actes IV Congrès International des Sciences Anthropologiques et Ethnologiques (Kenne, 1952), III, Viena, 1956.

"Some Aspects of Tapirapé Morals". Encyclopedia of Morals, New York, 1956. (51)

"As contribuiçōes de Maximiliano, principe de WiedNeuwied ao estudo dos indios do Brasil". Anais da II Reunião Brasileira de Antropologia (Bahia, 1955), Salvador, 1957.(52)

"A distinção entre pré-história e arqueologia". Anais da II Reunião Brasileira de Antropologia (Bahia, 1955), Salvador, 1957.

"Escola Vienense de Etnologia". Anhembi, XXV, $\mathrm{n}^{\circ}$ 74, S. Paulo, 1957.

"Primeira descrição sueca do Brasil". Anhembi, XXVI, no 78, S. Paulo, 1957.

"A casa-dos-homens". Anhembi, XXVII, no 80, S. Paulo, 1957. (53).

"Cândido Mariano da Silva Rondon 1865-1958". Revista do Museu Paulista, N.S., X, S. Paulo, 195658. (54) (55)

"Die Jaguarzwillinge: Mythen und Heibringergeschichten, Usprungssagen und Märchen brasilianischer Indianer", in Das Gesicht der Volker, Erich Roth-Verlag. Eisenach und Kassel, 1958.

"Transformação cultural entre os japonêses do vale do Rebeira". Folha da Manhã, 18/6. S. Paulo, 1958.

"Contribuiçōes à linguistica gê". Miscellanen Paul Rivet octogenario dicata, II, México, 1958.

"Paul Rivet". Anhembi, n. 90, S. Paulo, 1958. (56)

"O mêdo na cultura Tapirapé". Anhembi, n. 93, S. Paulo, 1958. (57)

"A 'Etnologia Histórica' no Brasil". O Estado de São Paulo, 28/9, S. Paulo, 1959. (58)

"Beiträge in deutcher Sprache zur Indianerforschung in Brasilien (1954-1958)". Mitteilungen aus dem Museum für Volkerkunde, XXV, Hamburg, 1959. (59)

"Curt Nimuendají". Jornal do Folclore, ano I, n. l, S. Paulo, 1960. (60)

"Antropologia Aplicada e o indigena brasileiro". Anhembi, XL, n. 119, S. Paulo, 1960. (61) (62)

"Kaui". Veröffentlichungen des Museums für Völkerkunde zu Leipzig, Heft 11, Berim, 1961

"Dringende Aufgaben für Amerikanisten". Südamerika, XII, Jg., Heft 1, Buenos Aires, 1961. (63) (64)

"Os carimbos do indio do Brasil". Revista do Museu Paulista, N.S., XIII, S. Paulo, 1961/62. (65) (66)

"Was ist seit 1500 aus dem Indianer Brasiliens geworden?". Akten cies 34 Internationalen Amerikanistenkongresses (Wien, 1960), Viena, 1962. (67)

"Escarificação e tatuagem entre os indios do Brasil". Humbold: Revista para o Mundo Luso-Brasileiro, ano 2, n. 3, Hamburgo, 1962. (68)

Métodos e resultados da ação indigenista no Brasil".
Revista de Antropologia, X, Nos. 1 e 2, S. Paulo, 1962. (69) (70)

"Métraux e a Etnologia Brasileira". Revista do Museu Paulista, N.S., XIV, S. Paulo, 1963. (71) (72)

"Sinopse da Bibliografia Critica da Etnologia Brasileira (1953-1960)". Arquivos do Instituto de Antropologia, I, n. 2, Natal, 1964. (73)

"O estado atual da Etnologia Brasileira". América Latina, ano 7, n. 4, Rio de Janeiro, 1964. (74)

"Xamanismo e aculturação". O Estado de São Paulo, ns. 409 e 410, S. Paulo, 1964.

"O xamanismo na aculturaçào de uma tribo tupi do Brasil Central". Revista do Museu Paulista, N.S., $X V$, S. Paulo, 1964. (75) (76) (77)

"Rondon $\mathrm{e} o$ indio, no centenário de seu nascimento: 5 de maio de 1865". Humboldt: Revista para o Mundo Luso-Brasileiro, ano V, n. 12, Hamburgo, 1965. (78)

"A contribuição de Anchieta ao conhecimento dos indios do Brasil". Anchietana, S. Paulo, 1965. (79)

"O xamanismo". Revista do Museu Paulista, N.S., $X V I$, S. Paulo, 1965/66.

"Harold Schultz 1909-1966". Revista do Museu Paulista, N.S., XVI, S. Paulo, 1965/66. (80) (81)

"Mondfinsternins bei den Tapirapé. Folk, VIII-IX, Copenhagen, 1966/67.

“Aspectos da organização social tapirapé: Tripartição, dualidade e graus de idade". Revista do Museu Paulista, N.S., XVII, S. Paulo, 1967. (82) (83)

"Bibliografia Critica da Etnologia Brasileira, Vol. II, Völkerkundliche Abhandlungen, Band IV, Hannover, 1868. (84)

"Zur Häuptlingsfrage bei den Tapirapè". Zeitschrift für Ethnologie, Band 93, Heft 1, n. 2, Braunschweig 1968. (85)

"Vertikale und horizontale Struktur in religiösen Weltbild südamerikanischer Indianer". Anthropos, 63/64, St. Augustin, 1968/69.

"Schweizer als Indianerforscher in Brasilien". Bulletin de la Societé Suisse des Américanistes, n. 33, Génève, 1969. (86)

Tapirapé: tribo tupi do Brasil Central. Brasiliana, vol. 17, Cia. Ed. Nacional e Ed. da Universidade de Sào Paulo, S. Paulo, 1970. (87)

Bibliografia Crítica da Etnologia Brasileira, Vol. I, Kraus Reprint, Völkerkundliche Abhandlungen, Vol. III, Nendeln/Liechtenstein, 1970.(88)

"Jaká-Rendy". Universitas - Revista de Cultura da Universidade Federal da Bahia, 67, Salvador, 1971.

"Einfürung" (Symposium Neue Ergebnisse der Indianerforschung in Brasilien). Verhandlungen des XXXVII Amerikanistenkongresses (Stuttgart-München, 1968), Band III, München, 1971. (89)

"Curt Nimuendaju (1883-1945)”. Humboldt, 28, München, 1973.

"O visitante". In Leituras de etnologia brasileira (org. E . Schaden). Cia. Ed. Nacional, S. Paulo, 1976.

Ensaios de etnologia brasileira, 2ః edição. Brasiliana, Cia. Ed. Nacional, S. Paulo, 1979. (90) 
SAMPAIO-SILVA, O. Herbert Baldus: vida e obra - Introduçāo ao indigenismo de um americanista teuto-brasileiro. Rev. do Museu de Arqueologia e Etnologia. S. Paulo, 2:91-114, 1992.

\section{Notas à Bibliografia de H. Baldus}

(1) Republicado, em lingua alemã, como apéndice de Indianerstudien im nordöstliche Chaco, 1931.

(2) Livro de 230 páginas. Neste mesmo ano, Baldus publicou, na Alemanha, a novela Madame Lynch.

(3) Traduzido para o francês - "La 'Mère commune" dans la mythologie de deux tribus sudaméricaines (Kágaba et Tumerehā) ${ }^{\boldsymbol{N}}$ - por Alfred Métraux, e publicado na Revista del Instituto de Etnologia, II, Tucumán, 1932. Também traduzido para o português - "A 'Mãe Comum' na Mitologia de Duas Tribos Sulamericanas (Kágaba e Tumerehã)" (1985) - , por Orlando Sampaio-Silva, como parte dos presentes estudos sobre a obra de Baldus.

(4) Este artigo, em português - “A sucessão hereditária dos indios Tereno" - , foi publicado também na Revista do Arquivo Municipal, XVII, S. Paulo, 1935, e consta do Ensaios de Etnologia Brasileira, 1937.

(5) Baldus trata, neste trabalho, dos indios Kaingá e Guaiaki. Sobre estes últimos, publicou outros artigos em 1943 e em 1946, tendo o autor destas notas encontrado referência a que estaria sendo publicado, post-mortem, o artigo "Die Guayaki", em Anthropos, St. Augustin (cf. Rev. do Museu Paulista, N.S., 68/69), porém não localizou-o em volumes de Anthropos, a partir de 1970.

(6) Livro de 346 págs., em sua primeira edição, prefaciada por Affonso d'Escragnole Taunay, que contém diversos ensaios que também foram publicados em periódicos, como no caso de "Os grupos de comer e os grupos de trabalho dos Tapirapén, publicado, em alemão, em Pindorama, 1, Jg., Heft 2/3, S. Paulo, 1937.

(7) Consta deste ensaio o comentário de Baldus à monografia "Guaná", de Max Schmidt, 1937.

(8) Publicado, em português - "A mudança de cultura entre indios no Brasil" - Ensaios de Etnologia Brasileira (1937).

(9) Também está contido, em português, no Diciond́rio de Etnologia e Sociologia (H. Baldus e E. Willems), 1939.

(10) 245 páginas.

(11) Com pequenas modificaçōes, foi publicado em América Indigena, IV, 1944, com o titulo: "Problemas Indigenistas no Brasil", e, no Boletim Geografico, ano $\mathrm{V}, \mathrm{n} .54,1947$.

(12) Republicado no Boletim Geogrdfico, n. 47, Rio de Janeiro, 1947.

(13) Baldus publicou, ainda, em 1940: "Nos sertões do Brasil de Frit: Krause", in Revista do Arquivo Municipal, LXVI, S. Paulo, e "A viagem pelo Brasil do Spix e Martius", idem, ibidem, $L X I X$.

(14) Publicado anteriormente em $O$ Estado de S. Paulo, 9, 11 e 16/9/43, e, posteriormente, no Manual Bibliográfico de Estudos Brasileiros, Rio de Janeiro, 1949. Em 1943, foi também publicado, em espanhol, na Revista Mexicana de Sociologia, V, n. 2, México, e, ampliado, veio a integrar a Introdução ao priemiro volume da Bibliografia Crítica da Etnologia Brasileira, 1954.
(15) Também foi publicado no $O$ Estado de S. Paulo, $22 / 6 / 44$.

(16) Esta comunicação, sendo mais ampla, contém o capítulo I de Os Tapirapé, tribo tupi no Brasil Central, livro editado em 1970.

(17) Sob esse titulo, Baldus publicou, nos anos subsequentes, até 1949, ensaios, na Revista do Arquivo Municipal, vols. XCVI ao CXXVII (exceto os vols. $C V$, CXXV e CXXVI), os quais foram reunidos mais tarde, "com modificaçōes e acréscimos", em seu livro com o mesmo titulo já referido.

(18) Contribuiu à área de Etnologia da SE edição do Pequeno Dicionário Brasileiro da Lingua Portuguesa, 1944, tendo sua colaboraçào sido reimpressa nas edições subsequentes do Dicionário.

(19) Publicado originariamente em $O$ Estado de $S$. Paulo, 22/11, S. Paulo, 1945, e, mais tarde, em versāo em alemão, no Deutsche-Blatter, XXIX, Santiago do Chile, 1946.

(20) Este necrológio foi publicado também no $O$ Estado de São Paulo, 6/1, S. Paulo, 1946; com acréscimos, em Sociologia, VIII, n. I, S. Paulo, 1946; na versāo em inglès (tradução de Charles Wagley), no American Anthropologist, XLVIII, n. 2, 1946; idem, em alemão, em Deutsche-Blatter, XXXI, Santiago do Chile, 1946, tendo sido reeditado, mais tarde, em 1960, 1962 e 1973, "com ligeiras modificaçōes".

(21) Publicado originariamente em Acta Americana, III, n. 4, México, 1945; posteriormente, no Boletim Geográfico, ano V, n. 53, Rio de Janeiro, 1947, e, atualizado e com complementaçōes, sob o titulo "Indianerforschung in Brasilien", no Sociologus, N.S., I, n. 1, Berlim, 1951.

(22) Em 1945, Baldus publicou a Introdução e Notas, em Os Caduveo, de Guido Boggiani.

(23) Livro de 121 páginas.

(24) Em 1946, pronunciou o discurso de paraninfo à turma de bacharéis em Ciências Politicas e Sociais, na Escola de Sociologia e Política de São Paulo, o qual foi publicado no Anuário da Escola Livre de Sociologia e Politica de São Paulo, S. Paulo, 1946.

(25) Grande parte deste artigo veio a ser publicada, mais tarde, com modificaçōes, in Tapirapé: Tribo tupi no Brasil Central, Cia. Ed. Nacional Ed. da USP, S. Paulo, 1970.

(26) $\mathrm{Em} \mathrm{1947,} \mathrm{foi} \mathrm{publicada} \mathrm{sua} \mathrm{Introduçāo} \mathrm{a} \mathrm{Indios}$ de Mato Grosso, de Erich Freundt.

(27) Republicado em Manual Bibliográfico de Estudos Brasileiros, Rio de Janeiro, 1949, sob o titulo "Etnologia".

(28) Republicado em Revisia do Arquivo Municipal, CXLII, S. Paulo, 1951.

(29) Os relatórios da Secção de Etnologia do Museu Paulista, sob a direçāo de $\mathbf{H}$. Baldus, foram publicados naquele mesmo veiculo, nos volumes dos anos: 1949, 1950, 1951, 1952, 1953, 1954, $1956 / 58,1959$ e 1960. 
SAMPAIO-SILVA. O. Herbert Baldus: vida e obra - Introduçào ao indigenismo de um americanista teuto-brasileiro. Rev. do Museu de Arqueologia e Etnologia. S. Paulo, 2:91-114, 1992.

(30) Em 1948, Baldus publicou, também:

- "Revista do Museu Paulista", $O$ Estado de $S$. Paulo, 17/4, S. Paulo;

- Introduçào e Notas a "Contribuiçōes para a Etnologia do Brasil", de Paul Ehrenreich, in Revista do Museu Paulista, N.S., II;

- Comentário à "Bibliografia morfológica humana, da América do Sul", de Juan Comas, ibidem;

- Comentários a "Prehistoric Ceramic Styles of Lowland South America", de Georg D. Howard, ibidem.

(31) Prefácio à Organização Social dos Tupinambá, de Florestan Fernandes, 1949. Foi também publicado em $O$ Estade de S. Paulo, 20 e 30/3, S. Paulo, 1949.

(32) Publicado novamente na Revista do Arquivo Municipal, CXLII, S. Paulo, 1951.

(33) Publicado anteriormente em $O$ Estado de S.Paulo, 1/12, S. Paulo, 1948.

(34) Resenhas de autoria de Baldus publicadas em 1949:

- a Hans Krieg: "Zwischen Anden und Atlantic", in Revista do Museu Paulista, N.S., III, S. Paulo;

- a Hilde Thurnwald: "Gengewartsprobleme Berliner Familien", ibidem.

(35) Publicada a versāo em português: Cultura, IV, Rio de Janeiro, 1951, sob o titulo: "Kanaschiwua". Esta matéria complementa o ensaio "Mitologia Karajá e Tereno", saido em Ensaios de Etnologia Brasileira, 1937.

(36) No mesmo ano foi editado em Anhembi, I, n. 2 S. Paulo, sob o titulo: "Entre indios norte-americanos".

(37) Reeditado no Boletim Bibliográfico de Antropologia Americana, XIII, parte I, México, 195I, e, em alemào, no Zeitschrift fïr Ethnologie, LXXVI, Heft 2, Braunschweig, 1951.

(38) Em 1951, Baldus publicou na Revista do Mus. Paulista, N.S., $V, \mathrm{~S}$. Paulo, os seguintes fragmentos $\mathrm{e}$ resenhas:

- a "Der Mensch geringer Naturbeherrschung", de Richard Thurnwald;

- a "Mythe, Mensch und Umwelt", de Ad. E. Jensen;

- a "Nomads of the long bow", de Allan R. Holmberg;

- a "Culture in crisis", de Laura Thompson.

(39) No mesmo ano foi reeditado na Revista do Mus. Paulisia, N.S., И, S. Paulo.

(40) Transcrito na Revista do Museu Júlio Castilhos e Arquivo Histórico do Rio Grande do Sul, n. 8, Porto Alegre, 1957, com omissão da bibliografia constante da primeira publicaçào.

(41) Baldus publicou ainda, em 1952:
- uma apresentaçào ao "Cenas da vida indigena", Álbum dos índios do Xingu, de Manuel Rodrigues Ferreira:

- resenha de "Mythos und Kult bei Naturvölkem", de Ad. E. Jensen, in Revista do Mus. Paulista, N.S., VI, S. Paulo;

- idem de "Des Menschengeistes Erwachen, Wachsen und Irren", de Richard Thurnwald, ibidem;

- idem de "Personality and Government", de Laura Thompson, ibidem;

- idem de "The Race Question in Modern Science", de Juan Comas, ibidem.

(42) Reproduzido em Revista do Museu Júlio de Castilhos e Arquivo Histórico do Rio Grande do Sul, n. 8, Porto Alegre, 1957.

(43) Outras publicaçōes de Baldus, em 1953

- "Psicologia Etica", in A Psicologia Moderna, de Otto Klineberg e cols.;

- prefaciou o "Mitos e lendas dos indios Taulipang e Arekuna", de Koch-Grünberg, Revista do Mus. Paulista, N.S., VII, S. Paulo;

- resenha de "Tupari", de Franz Gaspar, ibidem;

- idem de "Magic Books from Mexico", de C.

A. Burland, ibidem;

- fragmento sobre Julius F. Glück und F. Jäger: "Tribus", ibidem.

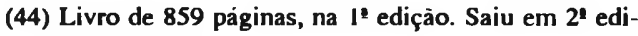
çào èn 1970.

(45) Trata-se de um suplemento ao Manual Bibliográfico de Estudos Brasileiros, 1949. Esta bibliografia está contida no Bibliografia Crítica da Ernologia Brasileira, 1954.

(46) Este trabalho è um resumo que complementa a Bibliografia Crírica da Etnologia Brasileira, 1954.

(47) Reimpresso eın Sïdamerika, IV, Buenos Aires, 1954.

(48) Em 1954, saiu a lume, com o Vinte e três indios resistem a civilização, de Harold Schultz, o prefácio de Baldus a essa obra.

(49) Editado em inglès: "The Ethnographical Study of the Brasilian Indian", Erlınos, $X X$, Stockholm, 1955

(50) Foram tambem publicados:

- "Der 31 Internationale Amerikanistenkongress", Sociologus, N.S., V, 12, Berlim, 1955. A ediçào italiana deste mesmo artigo saiu na Rivista di Etnografia, VIII -IX, Napoli, 1955.

Resenhas:

- "Maximilian Prinz zu Wied", de Röder e Trimborn, in Anhembi, n. 60, S. Paulo, 1955

- "Allgemeine Völkerkund”, de Kuntz Dittner, in Revista do Museu Paulista, N.S., IX, S. Paulo, 1955; 
SAMPAIO-SILVA, O. Herbert Baldus: vida e obra - Introduçào ao indigenismo de um americanista teuto-brasileiro. Rev. do Museu de Arqueologia e Etnologia. S. Paulo, 2:91-114, 1992.

- "Wild und Buschgeister in Südamerika", idem;

- "Las Poblaciones Indigenas de la Argentina, su origen, su pasado, su presente", de S. Canals Frau, idem.

(51) Em 1956, ainda publicou: “Der 32 Internationale Amerikanistenkongress", Sociologus, N.S., $V, 2$, Berlim, tendo sido publicada a versão em português, em Sociologia, XVII, n. 4, e a versào italiana, na Rivista di Einologia, $X$, Napoli.

(52) Versāo abreviada, em alemão: "Maximilian Prinz zu Wied in seiner Bedeutung für die Indianer Forschung in Brasilien", Proceedings of the Thirty-second International Congress of Americanists (Copenhagen, 1956), Copenhagen, 1958.

(53) Este artigo foi publicado em versão para o alemào, em Sociologus, VIII, Berlim, 1958.

(54) A revista Anhembi, n. 88, S. Paulo, 1958, reeditou este artigo.

(55) Na Revista do Mus. Paulista, N.S., X, S. Paulo, 1956-58, Baldus publicou as seguintes resenhas:

- "Wörterbuch der Soziologie", de Bernsdorf e Büllow;

— "Poesias", de José de Anchieta;

- "Die Wiener Schule der Völkerkunde", de J. Hackel.

(56) $\mathrm{O}$ artigo sobre Rivet, no ano seguinte, foi novamente publicado: Actas del XXXIII Congresso Internacional de Americanistas (San José da Costa Rica, 1958), I, San José da Costa Rica, 1959, e na Revista do Mus. Paulista, N.S., XI, S. Paulo, 1959.

(57) Saiu publicado, também, nos Anais da III Reunião Brasileira de Antropologia (1958), Recife, 1959, e, em inglês - "The Fear in tapirapé Culture" - in Selected Papers of the Fifih Internacional Congress of Anthropological and Ethnological Sciences (Philadelphia, 1956), Philadelphia, 1960.

(58) Neste artigo, o autor comenta o livro de Florestan Fernandes, A Emologia e a Sociologia no Brasil (1958), o que provocou a publicação, pelo autor comentado, de um artigo em resposta, cf. está referido no texto principal deste trabalho.

(59) Em 1959, Baldus publicou, na Revista do Mus. Paulista, N.S., S. Paulo, os seguintes fragmentos e resenhas:

- "S. P. I. - 1954";

- "Zwettler-Codex 420", de Pauke;

- "Das Alte Amerika", de Hermann Trimborn;

"Culturas e linguas indigenas do Brasil", de Darcy Ribeiro;

- "Arte plumária dos indios Kaapor", de Darcy Ribeiro e Berta G. Ribeiro;

- "Das Indianerbuch", de Eva Lips;

- “Tristes Trópicos”, de Claude Lévi-Strauss;

- "Mandurucu Religion", de Robert F. Murphy;
- "Lehrbuch der Völkerkunde", de Adam e Trimborn;

- "Völksdichtung der Ketschua", de J. Lara;

- "Etnografia de Mexico";

- "Sonderbauten südamerikanischer Naturvölker”, de Immina Schömig;

- "De passagem pelo Brasil e Portugal", de Johan Brelin;

- "Cott muss Peruaner sein", de Hans-Dietrich Disselhoff;

- "Volksdichtung der Keschua", de L. Flachskampf e M. Trimborn;

- "Les céramiques précolombiennes", de $\mathbf{H}$. Lekmann;

- "Die sozialökonomischen Verhältnisse bei den Azteken im 15 und 16. Jahrhundert", de Friedrich Katz;

- "Grundfragen menschlicher Gesellung", de R. Thurnwald;

- Lehrbuch der Völkerkund. Leonard Adam und $\mathrm{M}$. Trimborn.

(60) Trata-se de publicação, com pequenas modificaçōes, do artigo jả divulgado em 1945 e 1946, sendo novamente editado em Humboldr: Revista para o Mundo Luso-Brasileiro, ano 2, n. 5, Hamburg, 1962.

(61) Notas etnográficas, referentes principalmente aos Kaingang, ao "Diário de uma viagem pelo sertão de Sào Paulo, realizada em 1904", de Cornèlio Schmidt, publicado in Anais do Museu Paulista, $X V$, S. Paulo, 1961.

(62) Em 1960, Baldus fez acréscimos etnográficos à 10: edição do Pequeno Dicionário da Lingua Portuguêsa;

No mesmo ano, publicou notas e resenhas diversas:

- "O XXXIV Congresso Internacional de Americanistas". Sociologia, $X X$, n. 4, S. Paulo;

- "Die amerikanische 'Cultural Anthropology' und das Wertproblem", de Wolfgang Rudolf, in Revista do Mus. Paulista, N.S., XII, S. Paulo;

— "História da Cultura", de Birket-Smith, idem;

- "Ethnographic Interpretations", de A. L. Kroeber, idem;

- "Xingu", de Wustmann, idem;

- "Compêndio alemão de etnologia", Anhembi, n. 111 , S. Paulo;

- "Homenagem a Paul Rivet", idem, n. 118.

(63) Republicado em Akten des 34 Internationalen Amerikanistenkongress (Wien, 1960), Viena, 1962, e, no Bulletin of the International Committee on Urgente 
SAMPAIO-SILVA, O. Herbert Baldus: vida e obra - Introdução ao indigenismo de um americanista teuto-brasileiro. Rev. do Museu de Arqueologia e Etnologia. S. Paulo, 2:91-114, $1992 .$.

Anthropological and Ethnological Research, n. S, Viena, 1962.

(64) Baldus foi o compilador e selecionou estórias e lendas publicadas por diversos autores, tendo os textos sido adaptados por Afonso Schmidt, sendo publicados, com introdução de sua autoria, em "Estórias e lendas dos indios", Antologia llustrada do Folclore Brasileiro, $I$, S. Paulo, 1960.

(65) Um resumo deste substancioso ensaio foi publicado em lingua alemã: "Die Stempel der Indianer Barasiliens", Anthropos, LVI (Festschrift für P. Martin Gusinde), St. Augustin, 1962.

(66) Resenhas e comentários:

- "Chiliasmus und Nativismus", de Wilhelm E. Mühlmann, in Revista do Mus. Paulista, N.S., XIII, S. Paulo, 1961/62, saiu, mais tarde, publicado no Jornal Brasileiro de Psicologia, I, n. 1, 1964;

- "Grundprinzipien einer Periodizierung der Urgeschichte", de Irmgard Sellnow, in Revista do Mus. Paulista, N.S., XIII, S. Paulo, 1961/62;

- "Kinder der Erdgöttin", de Hans-Dietrich Disselhoff, idem;

- Comentário a Luiz Pericot y Garcia: America Indigena, tomo $I$, idem.

(67) Também publicado em Humboldt: Revista para 0 Mundo Luso-Brasileiro, n. 4, Hamburgo, 1962, e, mais tarde, no Brasilianisch Tage, in Ingelheim am Rhein, 25/4/1970.

(68) Este trabalho se constitui na maior parte do artigo "Os Tapirapé, tribo tupi no Brasil Central", in Rev. do Arquivo Municipal, CVI, S. Paulo, 1946, o qual, posteriormente modificado, veio a integrar o livro Tapirapé: Tribu tupi no Brasil Central, Cia. Ed. nacional-Ed. da USP, S. Paulo, 1970.

(69) Voltou a ser publicado: "Metodos y resultados de la acción indigenista en el Brasil", Actas y Memorias del XXXV Congresso Internacional de Americanistas, México, 1964, pois fora comunicação apresentada a este congresso, no México, a 21 de agosto de 1962.

(70) Prefaciou a História da Cultura, de Birket-Smith, 1962.

(71) Proferiu discurso, na qualidade de Presidente da VI Reunião Brasileira de Antropologia. Publicado in Revista do Mus. Paulista, N.S., XIV, S. Paulo, 1963.

(72) Prefaciou a 2" edição de A Organização Social dos Tupinambá, de Florestan Fernandes, S. Paulo, 1963.

(73) Versāo em inglês, sob o titulo: "Sinopsis of the Critical Bibliography of Brasilian Ethnology, 19531960", in Indians of Brazil in the Twentieth Century, Washington, 1967.

(74) Este trabalho complementa o "Sinopse da Bibliografia Critica da Etnologia Brasileira (1953-1960)" (1964). Foi publicado tambem no Bullletin of the International Comittee on Urgent Anthropological and Ethnological Research, № 7, Viena, 1965, sob o título: "Introdução ao simpósio sobre o estado atual de Etnologia na América Latina", saiu publicado na Actas y Memorias, III, do XXXVI Congresso intemacional de Americanistas, Sevilha, 1966.

(75) Outras publicaçōes do mesmo artigo: in Humboldt: Revista para o Mundo Luso-Brasileiro, XIV, Hamburgo, 1966, in Acras y Memorias del XXXV Congresso Internacional de Americanistas, III, Sevilha, 1966, e, em inglès, in Natives South Americans, Ethnology of the Least Known Continent, Little, Brown and Co., Boston, 1974.

(76) Prefaciou o Folclore Nacional, de A. Maynard de Araujo, S. Paulo, 1964.

(77) Resenhas e comentários:

- "Waika", de Otto Zerries, Revista do Mus. Paulista, N.S., XV, S. Paulo, 1964;

- "Die Tacana", de Hissink und Hahn, idem;

- H. Hartmann: Georg Catlin und Balduin Möllhausen, idem.

(78) Publicado, em lingua francesa, no Bulletin de la Societé Suisse des Américanistes, n. 29, Genève, 1965; saiu também, na Revista do Instituto Historico e Geográfico de Sāo Paulo, LXII, S. Paulo, 1966.

(79) Reeditado no Suplemento Antropológico de la Revista del Ateneo Paraguayo, vol. 3, n. 1-2, Assunção, 1968.

(80) Este necrológio, traduzido para o inglês por David Maybury Lewis, foi publicado em American Anthropologist, LXVII, n. 5, Menasha, 1966; identicamente editado em Humboldt, n. 16, Hamburgo, 1967.

(81) Resenhas e fragmentos:

- “Aculturaçào Indigena”, de Egon Schaden, Revista do Mus. Paulista, N.S., XVI, S. Paulo, 1965/66;

- "The use of some specific kinds of South American Indian Snuff and Related Paraphernalia", de S. Henry Wassen, idem;

- "Descriçào do Estado do Maranham, Pará, Corupa, Rio das Amazonas", de Mauricio de Heriarte, idem;

- "Manual de Arqueologia", de José Alcina Franck, idem.

(82) Este trabalho tambem foi publicado anteriomente em Acias y Memorias, XXXVII Congresso Internacional de Americanistas (Argentina, 1966), Vol. III, Buenos Aires, 1968, e, posteriormente, veio a constar do livro: Tapirapé, tribo tupi do Brasil Central, 1970.

(83) Resenhas e comentários:

- "Akawê-Shavante Society", de David Maybury-Lewis, in Revista do Mus. Paulista, N.S., XVII, S. Paulo, 1967; nesta resenha saiu também publicada em Sociologus, XVIII, Berlim, 1968;

- "Material Culture of the Waiwaii", de Jens Yde, idem; 
SAMPAIO-SILVA, O. Herbert Baldus: vida e obra - Introdução ao indigenismo de um americanista teuto-brasileiro. Rev. do Museu de Arqueologia e Etnologia. S. Paulo, 2:91-114, 1992.

- "Viaggi tra gli Indi", de Ettore Biocca, idem;

- P. Florian Paucke S.J. - Zwettler-Codex 420, II, idem.

(84) Com 864 páginas.

(85) Saiu publicado o Viagem pelo Brasil, de Spix e Martius, com Introduçào de Baldus, 1968.

(86) Publicado o Vagens ao Brasil, de Maximiliano,
Principe de Wied, identicamente com Introdução de Baldus, 1969.

(87) Contém artigos publicados sobre os indios Tapirapé, a partir de 1944 , aumentados e modificados.

(88) $2^{2}$ edição.

(89) Trata-se da Introduçào ("Einfürung") à Bibliografia Críica da Etnologia Brasileira, Vol. II (1968).

(90) Apresentação de Egon Schaden.

(Os estudos sobre H. BALDUS e sua obra, que possibilitaram a elaboração deste trabalho, foram concluídos pelo autor, prof. Orlando Sampaio-Silva, em setembro de 1985). 